\title{
Ultra-strong, transparent polytruxillamides derived from microbial photodimers
}

Seiji Tateyama ${ }^{1 \dagger}$, Shunsuke Masuo ${ }^{2 \dagger}$, Phruetchika Suvannasara ${ }^{1,3}$, Yuuki Oka ${ }^{1}$, Akio

Miyazato ${ }^{1}$, Katsuaki Yasaki ${ }^{1}$, Thapong Teerawatananond ${ }^{3}$, Nongnuj Muangsin ${ }^{3}$, Shengmin

Zhou $^{2}$, Yukie Kawasaki ${ }^{2}$, Longbao Zhu ${ }^{4}$, Zhemin Zhou ${ }^{4}$, Naoki Takaya ${ }^{2 *}$, and Tatsuo

Kaneko $^{1 *}(\dagger$ equal contribution)

\section{Affiliations:}

${ }^{1}$ School of Materials Science, Japan Advanced Institute of Science and Technology, 1-1

Asahidai, Nomi, Ishikawa, 923-1292 Japan.

${ }^{2}$ Faculty of Life and Environmental Sciences, University of Tsukuba, 1-1-1 Ten-nodai, Tsukuba, Ibaraki 305-8572, Japan.

${ }^{3}$ Bioorganic Chemistry and Biomaterials Research Group, Department of Chemistry, Faculty of Science, Chulalongkorn University, Bangkok 10330, Thailand

${ }^{4}$ Key Laboratory of Industrial Biotechnology, Ministry of Education, School of

Biotechnology, Jiangnan University, Wuxi 214122, China.

*Email address:kaneko@jaist.ac.jp, takaya.naoki.ge@u.tsukuba.ac.jp 


\section{Supporting information}

\section{Table of contents}

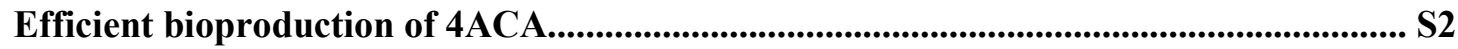

Materials and Methods

Biological experiments

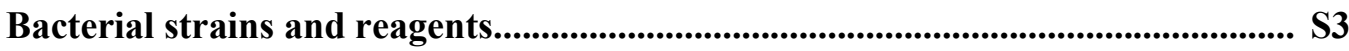

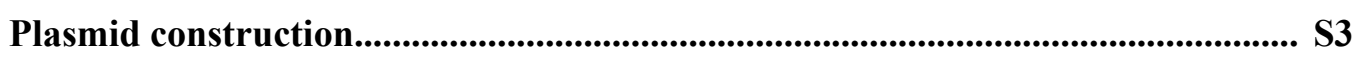

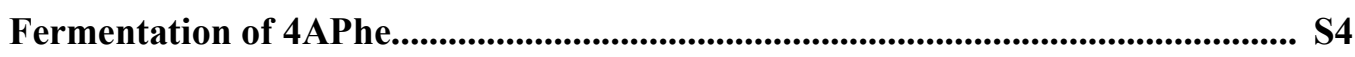

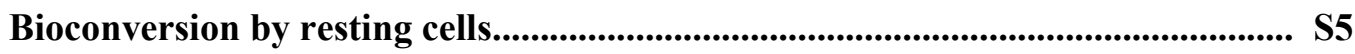

Purification of 4APhe and 4ACA.......................................................................... S6

Other methods............................................................................................................................ S6

Chemical experiments

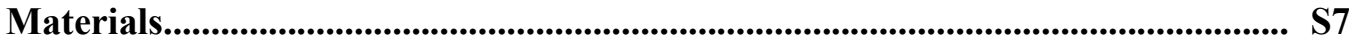

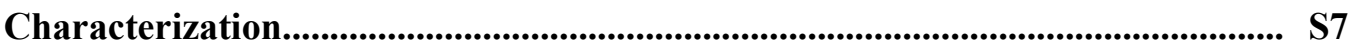

UV irradiation.................................................................................................................. 58

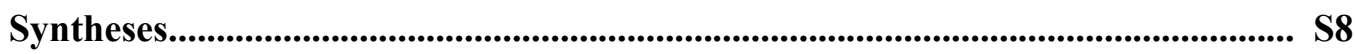

Degradation of aromatic polyamide 7............................................................. S12

X-ray crystallography........................................................................................................................ S12

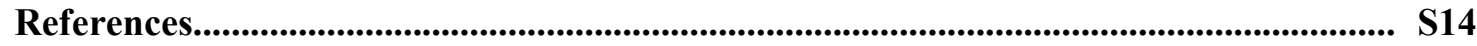

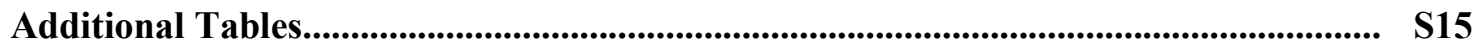

Additional Figures................................................................................................................... S21 


\section{Efficient bioproduction of 4ACA}

An artificial biosynthetic route for $4 \mathrm{ACA}^{1}$ was created in Escherichia coli cells, which fermented 4-aminophenylalanine (4APhe) from glucose, and then deaminated to 4ACA (Figure S1A). ${ }^{1}$ To increase production yield, combinations of the pap $A B C$ genes from two bacterial strains and E. coli pabA and $p a b B$ in the folate biosynthesis pathway, and host bacterial strains were examined (Tables S1). After optimizing culture conditions, Streptomyces venezuelae papA and $S$. pristinaespiralis papBC produced the highest level of 4 APhe $(0.6 \mathrm{~g} / \mathrm{L})$ (Table S2). The gene disruptant of $p h e A$, which is required phenylalanine for growth, avoids competition with PapA for its chorismate substrate, and produced 1.5-fold more 4APhe (Table S3). Among the E. coli aminotransferase genes $\operatorname{tyr} B$ and $\operatorname{asp} C$, overexpression of tyrB improved the 4APhe production (Table S3). Fed-batch cultures of the pheA gene disruptant overexpressing pap $A B C$ and tyrB (NST(DE3)/ApheLA/papABC/tyrB) produced $2.2 \mathrm{~g} / \mathrm{L}$ 4APhe from glucose (Figure S1B). Column chromatography purified the produced 4 APhe from culture medium with $85 \%$ purity and $90 \%$ yield (Figure S1C).

Arabidopsis thaliana phenylalanine ammonia lyase $4(\text { AtPal4 })^{2}$ deaminates 4APhe to 4ACA. This study overexpressed a PAL from Hordeum vulgare $(H \nu \mathrm{PAL})^{3}$ and Rhodotorula glutinis $(\operatorname{RgPAL})^{4}$ in E. coli BL21(DE3) and revealed that the strain producing RgPal deaminated 4APhe to 4ACA at 10 -fold higher rate than those producing $A t \mathrm{Pal} 4$ and $H v \mathrm{Pal}$ (Table S4). The resting-cell reaction of the strain overproducing $\operatorname{RgPAL}$ yielded $2.2 \mathrm{~g} / \mathrm{L}$ of 4ACA from 4APhe, which was 30-fold more than that by the AtPal4 system (Figure S2A). ${ }^{1}$ Purified 4ACA from the reaction was yellow powder with $90 \%$ purity (Figure S2B). 


\section{Materials and Methods}

\section{Biological experiments}

\section{Bacterial strains and reagents}

The Escherichia coli strain NST37 (ATCC31882) (aroF $F^{f b r}$, aro $G^{f b r}$, tyrA, tyrR, phe ${ }^{f b r}$, pheAo, $\operatorname{trpE}$ ) that produces phenylalanine was obtained from American Type Culture Collection (Manassas, MD, USA). Escherichia coli NST37 (DE3) was generated using $\lambda$ DE3 Lysogenization kits (Novagen, Madison, WI, USA) and proteins were produced from Escherichia coli BL21-Gold(DE3), BL21-Gold(DE3)pLysS, BL21-CodonPlus(DE3)-RIPL, BL21-CodonPlus(DE3)-RIL(Novagen), HMS174(DE3) and HMS174(DE3) pLysS (Merck). E. coli NST37(DE3)/ApheLA is a gene disruptant of pheA derived from E. coli NST37 (DE3) as described. ${ }^{5}$ Plasmids were constructed using bacterial strain JM109. Both 4-aminophenylalanine and 4-aminocinnamic acid were obtained from Tokyo Chemical Industry (Tokyo, Japan). PrimeSTAR HS DNA Polymerase and restriction enzymes were provided by Takara Bio Inc. (Shiga, Japan). Ligation high ver. 2 was from Toyobo Co. (Osaka, Japan).

\section{Plasmid construction}

Supplementary Table S5 lists the primers used in this study. The papA gene was amplified by PCR from $S$. venezuelae ATCC10712 genomic DNA with the primer pair SvpAF and SvpAR. The PCR product was digested with appropriate enzymes and cloned into plasmid pET-duet1 and pRSF-duet1 (Novagen) that were digested with the same enzymes, to create pET-SvPapA and pRSF-SvPapA. The $p a p B$ and papC genes from $S$. venezuelae were amplified by PCR with the primer pairs SvpBF/SvpBR and SvpCF/SvpCR, digested with the appropriate enzymes, and sequentially cloned into the tandem multi cloning site of pET-duet1 and pRSF-duet1 to generate 
pET-SvPapBC and pET-SvPapBC. The papB and papC genes from S. pristinaespiralis ATCC 25486 and the $p a b A$ and $p a b B$ genes from E. coli MG1655 were cloned using the same strategy into pET-duet1 and pRSF-duet1, respectively, to generate pET-SpPapBC, pRSF-SpPapBC, pET-EcPabAB and pRSF-EcPabAB.

The $\operatorname{tyr} B$ and $\operatorname{asp} C$ genes were amplified from the $E$. coli genome by PCR using the primer pairs $\mathrm{TyBF} / \mathrm{TyBR}$, and $\mathrm{AsCF} / \mathrm{AsCR}$, digested with restriction enzymes and cloned into pCDFduet-1 to generate pCDF-tyrB, and pCDF-aspC, respectively. After restriction digestion, the aspC gene was also cloned into pCDF-tyrB to generate pCDF-tyrBaspC. The A. thaliana pal4 ${ }^{2}$ and H. vulgare pal $^{3}$ genes were amplified from cDNA using the primer pairs AtPF/AtPR and $\mathrm{HvPF} / \mathrm{HvPR}$, digested with the appropriate enzymes and cloned into plasmid $\mathrm{pHSG}^{6}$ and $\mathrm{pET} 28 \mathrm{a}$ respectively, to create pHSG-AtPal4 and pET-HvPal, and RgPAL was produced using pet-28a-pal. ${ }^{4}$

\section{Fermentation of 4 APhe}

Cells were grown in growth M9 medium $\left(6 \mathrm{~g} \mathrm{Na}_{2} \mathrm{HPO}_{4}, 3 \mathrm{~g} \mathrm{KH}_{2} \mathrm{PO}_{4}, 0.5 \mathrm{~g} \mathrm{NaCl}, 2 \mathrm{~g}\right.$ $\mathrm{NH}_{4} \mathrm{Cl}, 0.5 \mathrm{~g} \mathrm{MgSO}_{4} 7 \mathrm{H}_{2} \mathrm{O}, 15 \mathrm{mg} \mathrm{CaCl}_{2}, 50 \mathrm{mg}$ Thiamin- $\mathrm{HCl}$ and $2 \mathrm{~mL} / \mathrm{L}$ of Trace element solution $)^{5}$ containing $1 \%$ glucose unless otherwise stated. Sodium ampicillin $\left(100 \mu \mathrm{g} \mathrm{ml}^{-1}\right)$, kanamycin sulfate $\left(40 \mu \mathrm{g} \mathrm{ml}^{-1}\right)$ and chloramphenicol $\left(35 \mu \mathrm{g} \mathrm{ml}^{-1}\right)$ were added to maintain plasmids. Tyrosine (20 $\left.\mathrm{mg} \mathrm{l}^{-1}\right)$ and tryptophan $\left(20 \mathrm{mg} \mathrm{l}^{-1}\right)$ were used to culture NST37(DE3). Tyrosine (20 mg $\left.\mathrm{l}^{-1}\right)$, tryptophan $\left(20 \mathrm{mg}^{-1}\right)$ and phenylalanine $\left(20 \mathrm{mg} \mathrm{l}^{-1}\right)$ were used to culture NST37(DE3)/ $\Delta$ pheA. Cells were pre-cultured in test tubes containing $5 \mathrm{~mL}$ of medium at $28^{\circ} \mathrm{C}$ overnight on a rotary shaker $(300 \mathrm{rpm})$, and diluted 1:100 into $100 \mathrm{~mL}$ of fresh medium in 500-mL conical flasks. Cells were grown to an optical density at $600 \mathrm{~nm}$ of 0.6 at $30^{\circ} \mathrm{C}$ and then $0.1 \mathrm{mM}$ 
isopropyl- $\beta$-d-thiogalactoside (IPTG) was added. Fed-batch cultures were agitated at $600 \mathrm{rpm}$ and $30^{\circ} \mathrm{C}$ with $0.6 \mathrm{~L} \mathrm{~min}^{-1}$ of aeration in a 1.0-L fermenter (BMJ-01, Biott, Japan) containing $0.5 \mathrm{~L}$ of fermentation medium. The $\mathrm{pH}$ was monitored using a $\mathrm{pH}$ electrode and maintained between 7.0 and 7.1 by adding $10 \%$ ammonia. Peristaltic pumps fed the cultures with a solution containing $500 \mathrm{~g} / \mathrm{L}$ of glucose.

\section{Bioconversion by resting cells}

Escherichia coli BL21(DE3) harboring either pHSG-AtPal4, pET-HvPal or pET-28a-pal were grown in test tubes containing $3 \mathrm{~mL}$ of LB-medium at $37^{\circ} \mathrm{C}$ overnight on a rotary shaker $(300 \mathrm{rpm})$, and diluted 1:100 into $100 \mathrm{~mL}$ of fresh LB-medium in 500-mL conical flasks. Cells were grown to an optical density at $600 \mathrm{~nm}$ of 0.6 at $30^{\circ} \mathrm{C}$, then $0.5 \mathrm{mM}$ IPTG was added and the cells were further incubate for $6 \mathrm{~h}$. The cells were collected and washed with reaction buffer (100 mM potassium phosphate; $\mathrm{pH}$ 8.0). Washed cells were incubated in $1 \mathrm{~mL}$ of reaction buffer containing $2.5 \mathrm{~g} \mathrm{~L}^{-1} 4 \mathrm{APhe}$.

\section{Purification of $4 A$ Phe and $4 A C A$}

Bacterial cells were removed from culture broth by centrifugation and supernatants were applied to AG50W-X8 ion-exchange resin columns (Bio-Rad). Bound compounds were eluted with $2.5 \%$ ammonia solution and evaporated. The resulting pellet was dissolved in $0.1 \mathrm{M} \mathrm{HCl}$ and applied to a reverse phase Wakogel 100C18 column (Wako Pure Chemical Industries, Osaka, Japan). Unbound fractions were collected to obtain 4APhe. Culture supernatants were acidified with $1 \mathrm{M} \mathrm{HCl}$, extracted with ethyl acetate and evaporated to purify 4ACA. The resulting pellet was 
dissolved in acetone and debris was removed by centrifugation. Five volume of saturated $\mathrm{NaCl}$ was added to the supernatant and incubated for $10 \mathrm{~min}$ at $4^{\circ} \mathrm{C}$. Precipitated $4 \mathrm{ACA}$ was collected by filtration and washed with saturated $\mathrm{NaCl}$ and then the purity was estimated by HPLC

\section{Other methods}

We quantified 4APhe and 4ACA by reverse phase HPLC (1200 infinity series: Hewlett Packard $)$ equipped with a Purospher Star RP-18 end-capped column $(250 \times 4.6 \mathrm{~mm}$; particle size; 5 $\mu \mathrm{m})$ (Merck). Cell-free extracts were prepared as describe. ${ }^{4}$ Phenylalanine ammonia-lyase was assayed based on subsequent changes in absorbance at $290 \mathrm{~nm}$ as described. ${ }^{7}$ Changes in absorbance at $315 \mathrm{~nm}$ were monitored to assay 4APhe ammonia-lyase. 


\section{Chemical experiments}

\section{Materials}

4-Aminocinnamic acid, 2,5-frandicarboxylic acid, succinyl chloride, glutaryl dichloride, adipoyl chloride, suberoyl chloride, azelaoyl chloride and sebacoyl chloride were purchased from Tokyo Chemical Industry and used as received. Pimeloyl chloride was purchased from Sigma-Aldrich. Trimethylchlorosilane was purchased from Shin-Etsu Chemicals. Hydrochloric acid, sodium hydroxide, sodium sulfate, acetic anhydride, triphenylphosphite, acetone, hexane,

ethyl acetate, methanol, dichloromethane, dehydrated pyridine, dehydrated $N$-methylpyrolidone and dehydrated $N, N$-dimethylacetamide were purchased from Kanto Chemical and used as received.

\section{Characterization}

High-resolution NMR spectra $\left({ }^{1} \mathrm{H}\right.$ at $400 \mathrm{MHz},{ }^{13} \mathrm{C}$ at $\left.100 \mathrm{MHz}\right)$ were obtained on a Bruker NMR spectrometer model AVANCE III 400 with BBFO plus ATMA probe in DMSO- $d_{6}$. Analyses by FT-ICR MS were performed on ESI or MALDI ion source equipped with a $9.4 \mathrm{~T}$ superconducting magnet (Bruker daltonics Corp., Solarix-JA). Size exclusion chromatography (SEC) was performed on a Shodex GPC-101 with the combination of Shodex KD-803 (exclusion limit: PEG, $7 \times 10^{4}$ ) and KD-804 (exclusion limit: PEG, $\left.4 \times 10^{5}\right)$ using DMF as an eluent $(1$ $\mathrm{mL} / \mathrm{min}$ ). Thermal stability of polymer was investigated by SEIKO SSC/5200 TGA under nitrogen from 50 to $750{ }^{\circ} \mathrm{C}$ at heating rate of $10^{\circ} \mathrm{C} / \mathrm{min}$. Glass transition temperature measurement was done by SEIKO X-DSC7000T differential scanning calorimeter. The measurement was carried out from 50 to $300{ }^{\circ} \mathrm{C}$ at a heating rate of $10^{\circ} \mathrm{C} / \mathrm{min}$ with $5 \mathrm{mg}$ sample. Mechanical strength was measured by using a tensile testing machine (3365-L5, Instron, Canton, MA, USA). 


\section{UV irradiation}

For photo-dimerization reaction of derivatives of compound 1, UV irradiation was performed on a $100 \mathrm{~W}$ high pressure Hg lamp (Omni Cure S1000, EXFO Photonic Solution Inc.) with 250-450 $\mathrm{nm}$ band-pass filter. For photo cleavage of 7, UV irradiation was carried out on a Xe lamp (300 W, Asahi Spectra Co. Ltd.; MAX-303) equipped with 254 nm band-pass filter.

\section{Synthesis of 4-aminocinnamic acid hydrochloride}

Concentrated hydrochloric acid $(10 \mathrm{ml}, 0.12 \mathrm{~mol})$ was added dropwise to acetone $(350 \mathrm{ml})$ solution of 1 (16.3 g, $0.10 \mathrm{~mol})$. After the reaction mixture was stirred for $1 \mathrm{~h}$ at room temperature, formed white solid was filtered, and washed with acetone. The product was pure enough for further

reaction, and was determined to be compound 2 (18.7 g, 94\% yield). ${ }^{1} \mathrm{H}$ NMR (400 MHz, DMSO- $\left.d_{6}\right): \delta 6.50(\mathrm{~d}, 1 \mathrm{H}, J=16.0 \mathrm{~Hz}), 7.34(\mathrm{~d}, 2 \mathrm{H}, J=8.4 \mathrm{~Hz}), 7.55(\mathrm{~d}, 1 \mathrm{H}, J=16.0 \mathrm{~Hz}), 7.73(\mathrm{~d}$, $2 \mathrm{H}, J=8.4 \mathrm{~Hz}), 9.98(\mathrm{~s}, 3 \mathrm{H}) .{ }^{13} \mathrm{C}$ NMR $\left(100 \mathrm{MHz}, \mathrm{DMSO}-d_{6}\right): \delta 118.9,122.0,129.5,131.8,136.6$, $143.0,167.5$

\section{Synthesis of 4,4'-diamino- $\alpha$-truxillic acid dihydrochloride}

Hexane dispersion $(20 \mathrm{ml})$ of $2(1.0 \mathrm{~g}, 5.0 \mathrm{mmol})$ was placed in round bottom flask and irradiated UV using 250-450 $\mathrm{nm}$ Mercury lamp for $25 \mathrm{~h}$. Formed precipitate was filtered and dried in vacuo, compound 3 was obtained as white powder $(1.0 \mathrm{~g}, 100 \%) .{ }^{1} \mathrm{H}$ NMR $(400 \mathrm{MHz}$, DMSO- $\left.d_{6}\right): \delta 3.82(\mathrm{dd}, 2 \mathrm{H}, J=7.7,9.6 \mathrm{~Hz}), 4.30(\mathrm{dd}, 2 \mathrm{H}, J=7.7 \mathrm{~Hz}, 9.6 \mathrm{~Hz}), 7.33(\mathrm{~d}, 4 \mathrm{H}, J=7.7$ $\mathrm{Hz}), 7.45(\mathrm{~d}, 4 \mathrm{H}, J=7.7 \mathrm{~Hz}), 10.37$ (s, 6H), 12.07 (s, 2H). ${ }^{13} \mathrm{C}$ NMR (100 MHz, DMSO- $\left.d_{6}\right): \delta 40.4$, 
46.0, 122.8, 128.9, 130.6, 139.1, 172.6. FT-ICR MS (ESI) calcd for $\left[\mathrm{M}-\mathrm{H}, \mathrm{C}_{18} \mathrm{H}_{17} \mathrm{~N}_{2} \mathrm{O}_{4}\right]^{-}: 325.1188$, found 325.1190 .

\section{Synthesis of 4,4'-diamino- $\alpha$-truxillic acid dimethyl ester}

To a solution of $3(9.80 \mathrm{~g}, 24.5 \mathrm{mmol})$ in methanol $(40 \mathrm{ml})$, trimethylchlorosilane $(12.4 \mathrm{ml}$, 98.0mmol) was added dropwise. The reaction mixture was stirred under nitrogen atmosphere at room temperature for $42 \mathrm{~h}$. Formed precipitate was filtered and neutralized by $1 \mathrm{~N} \mathrm{NaOH}$ aqueous. The crude product was extracted by ethyl acetate $(280 \mathrm{ml})$ and washed with water, subsequently dried over $\mathrm{Na}_{2} \mathrm{SO}_{4}$. The solution was filtered and dried in vacuo, compound $\mathbf{4}$ was obtained as white powder (10.0 g, 95.5\%). ${ }^{1} \mathrm{H}$ NMR (400 MHz, DMSO- $\left.d_{6}\right): \delta 3.27(\mathrm{~s}, 6 \mathrm{H}), 3.72(\mathrm{dd}, 2 \mathrm{H}, J=7.4,10.2$ $\mathrm{Hz}), 4.11(\mathrm{dd}, 2 \mathrm{H}, J=7.4 \mathrm{~Hz}, 10.1 \mathrm{~Hz}), 5.00$ (s, 4H), 6.51 (d, 4H, $J=8.4 \mathrm{~Hz}), 6.95$ (d, 4H, $J=8.4$

Hz). ${ }^{13} \mathrm{C}$ NMR (100 MHz, DMSO- $\left.d_{6}\right): \delta 40.4,46.6,51.0,113.7,125.7,128.0,147.3,172.1$. FT-ICR MS (ESI) calcd for $\left[\mathrm{M}+\mathrm{H}, \mathrm{C}_{20} \mathrm{H}_{23} \mathrm{~N}_{2} \mathrm{O}_{4}\right]^{+}: 355.1658$, found 355.1663 .

\section{Synthesis of 4-acetamidocinnamic acid}

Acetic anhydride $(20 \mathrm{ml}, 212 \mathrm{mmol})$ was added to a solution of $1(10.0 \mathrm{~g}, 61.3 \mathrm{mmol})$ in methanol $(180 \mathrm{ml})$. The solution was stirred at room temperature for 12 hours. Formed precipitate was filtered and washed with methanol and dried in reduced pressure. The obtained white powder was determined to be compound $5(10.3 \mathrm{~g}, 81.8 \%)$. ${ }^{1} \mathrm{H}$ NMR (400 MHz, DMSO- $\left.d_{6}\right): \delta 2.05(\mathrm{~s}, 3 \mathrm{H})$, $6.40(\mathrm{~d}, 1 \mathrm{H}, J=16.0 \mathrm{~Hz}), 7.52(\mathrm{~d}, 1 \mathrm{H}, J=16.0 \mathrm{~Hz}), 7.59(\mathrm{~d}, 2 \mathrm{H}, J=9.0 \mathrm{~Hz}), 7.62(\mathrm{~d}, 2 \mathrm{H}, J=9.0$ $\mathrm{Hz}), 10.10(\mathrm{~s}, 1 \mathrm{H}), 12.25(\mathrm{~s}, 1 \mathrm{H}) .{ }^{13} \mathrm{C} \mathrm{NMR}\left(100 \mathrm{MHz}, \mathrm{DMSO}-d_{6}\right): \delta 24.1,117.3,119.0,128.9$, 
129.0, 141.2, 143.7, 167.8, 168.7. FT-ICR MS (SALDI) calcd for $\left[\mathrm{M}+\mathrm{Na}, \mathrm{C}_{11} \mathrm{H}_{11} \mathrm{NO}_{3} \mathrm{Na}\right]^{+}$: 228.0637, found 228.0617 .

\section{Synthesis of 4,4'-diacetamido- $\alpha$-truxillic acid}

Dichloromethane dispersion $(50 \mathrm{ml})$ of $\mathbf{5}(1.0 \mathrm{~g}, 4.87 \mathrm{mmol})$ was placed in round bottom flask and irradiated UV using 250-450 nm Mercury lamp for $4 \mathrm{~h}$. Formed precipitate was filtered and dried in vacuo, compound 6 was obtained as white powder $(0.93 \mathrm{~g}, 93 \%) .{ }^{1} \mathrm{H}$ NMR (400 MHz, DMSO- $\left.d_{6}\right): \delta 2.03(\mathrm{~s}, 6 \mathrm{H}), 3.73(\mathrm{dd}, 2 \mathrm{H}, J=7.4,10.2 \mathrm{~Hz}), 4.20(\mathrm{dd}, 2 \mathrm{H}, J=7.4 \mathrm{~Hz}, 10.2 \mathrm{~Hz}), 7.25$ $(\mathrm{d}, 4 \mathrm{H}, J=8.5 \mathrm{~Hz}), 7.50(\mathrm{~d}, 4 \mathrm{H}, J=8.5 \mathrm{~Hz}), 9.89(\mathrm{~s}, 2 \mathrm{H}), 12.04(\mathrm{~s}, 2 \mathrm{H}) .{ }^{13} \mathrm{C} \mathrm{NMR}(100 \mathrm{MHz}$ DMSO- $\left.d_{6}\right): \delta 24.1,40.8,46.6,119.1,128.1,134.2,138.1,168.5,173.2$. FT-ICR MS (SALDI) calcd for $\left[\mathrm{M}+\mathrm{Na}, \mathrm{C}_{22} \mathrm{H}_{22} \mathrm{~N}_{2} \mathrm{O}_{6} \mathrm{Na}\right]^{+}$: 433.1376, found 433.1364.

\section{Synthesis of poly\{(4,4'-diyl- $\alpha$-truxillic acid dimethylester) 4,4'-diacetamido- $\alpha$-truxillamide\}}

To compounds $4(1.73 \mathrm{~g}, 4.88 \mathrm{mmol})$ and $6(1.99 \mathrm{~g}, 4.85 \mathrm{mmol})$ placed in a flask under nitrogen atmosphere, N-methylpyrrolidone $(4.8 \mathrm{ml})$, tripheylphosphite $(1.4 \mathrm{ml}, 5.35 \mathrm{mmol})$ and pyridine (2.4 ml, $29.8 \mathrm{mmol})$ ware added. After the reaction mixture was stirred for 2 hours at 100 ${ }^{\circ} \mathrm{C}$, the solution was diluted in NMP $(50 \mathrm{ml})$, then added dropwise into methanol $(1000 \mathrm{ml})$ to precipitate the polymer which was collected filtration and dried in reduced pressure. The obtained fibril was determined to be aromatic polyamide 7 (3.34 g, $94.6 \%$ ). ${ }^{1} \mathrm{H}$ NMR (400 MHz, DMSO- $d_{6}$ ): $\delta 1.95\left(6 \mathrm{H}, \mathrm{NHCOCH}_{3}\right), 3.13\left(6 \mathrm{H}, \mathrm{COOCH}_{3}\right), 3.79-4.36(8 \mathrm{H}$, cyclobutane $), 7.00-7.49(16 \mathrm{H}$, arom.), 9.71-9.93 (4H, NH). SEC: $M_{\mathrm{n}}=1.02 \times 10^{4}, M_{\mathrm{w}}=2.10 \times 10^{4}, \mathrm{PDI}=2.06$. 
Synthesis of aliphatic polyamides with furan backbone Poly\{(4,4'-diyl-a-truxillic acid dimethylester) 2,5-frandicarboxylamide\}

To 4 (100.9 mg, $0.29 \mathrm{mmol})$ and 2,5-frandicarboxylic acid (44.8 $\mathrm{mg}, 0.29 \mathrm{mmol})$ placed in a flask under nitrogen atmosphere, N-methylpyrrolidone $(0.28 \mathrm{ml})$, tripheylphosphite $(81.2 \mu \mathrm{L}, 0.27$ mmol) and pyridine $(280 \mu \mathrm{L}, 2.98 \mathrm{mmol})$ ware added. After the reaction mixture was stirred for 24 hours at $110{ }^{\circ} \mathrm{C}$, the solution was diluted in NMP $(1.5 \mathrm{ml})$, then added dropwise into methanol (60 $\mathrm{ml}$ ) to precipitate target polymer which was collected filtration and dried in reduced pressure. The obtained fibril was determined to be polyamide with furan backbone $8(0.13 \mathrm{~g}, 96.3 \%)$. ${ }^{1} \mathrm{H}$ NMR (400 MHz, DMSO-d $\left.)_{6}\right): \delta 3.23\left(6 \mathrm{H}, \mathrm{COOCH}_{3}\right), 3.38-4.40(4 \mathrm{H}$, cyclobutane $), 7.30-7.73(10 \mathrm{H}$, arom.), $10.3(2 \mathrm{H}, \mathrm{NH})$. SEC: $M_{\mathrm{n}}=2.73 \times 10^{4}, M_{\mathrm{w}}=5.43 \times 10^{4}, \mathrm{PDI}=1.99$.

Syntheses of aliphatic polyamides with linear alkyl chain poly\{(4,4'-diyl-a-truxillic acid dimethylester) a,w-alkyloylamide\} 9-Cn (n refers the number of carbon atoms in the aliphatic diacids)

Typical example of syntheses of aliphatic polyamides is given for the synthesis of polyamide from 4 with suberoyl chloride. To $4(121.1 \mathrm{mg}, 0.34 \mathrm{mmol})$ placed in a flask under nitrogen atmosphere, anhydrous $N, N$-dimethylacetamide (DMAc) $(350 \mu \mathrm{L})$, anhydrous pyridine $(70 \mu \mathrm{L})$ and suberoyl chloride (50 $\mu \mathrm{L}, 0.34 \mathrm{mmol}$ ) were added. After the reaction mixture was stirred for $3 \mathrm{~h}$ at room temperature, the solution was diluted in DMAc $(1.5 \mathrm{~mL})$, and then added into methanol (40 $\mathrm{ml}$ ) to precipitate. The obtained fibril was dried in reduced pressure and determined to be polyamide with hexamethylene alkyl chains 9-C8 $(90.5 \mathrm{mg}, 57.0 \%)$. Aliphatic polyamides 9 with carbon number of C5-C10 were synthesized by a similar method. 
Syntheses of terpolyamides with linear alkyl chain 10-Cn (n refers the number of carbon atoms in the aliphatic diacids)

Typical example of syntheses of terpolyamides is given for the synthesis of terpolyamide from 4 with 6 and adipic acid. To $4(0.20 \mathrm{~g}, 0.56 \mathrm{mmol})$ placed in a flask under nitrogen atmosphere, anhydrous N-methylpyrrolidone (NMP) $(560 \mu \mathrm{L})$, anhydrous pyridine (276 $\mu \mathrm{L}, 3.43 \mathrm{mmol})$, triphenyl phosphite $(161 \mu \mathrm{L}, 0.61 \mathrm{mmol}), 6(0.11 \mathrm{~g}, 0.28 \mathrm{mmol})$ and adipic acid $(41.9 \mathrm{mg}, 0.28$ mmol) were added. After the reaction mixture was stirred for 24 hours at $110^{\circ} \mathrm{C}$, the solution was diluted in NMP $(1.5 \mathrm{ml})$, then added dropwise into methanol $(60 \mathrm{ml})$ to precipitate target terpolymer which was collected filtration and dried in reduced pressure. The obtained fibril was determined to be terpolyamide with linear alkyl chain 10-C6 (0.26 g, 78.8\%). Terpolyamides $\mathbf{1 0}$ with carbon number of C4-C10 were synthesized by a similar method.

\section{Degradation of aromatic polyamide 7}

Concentrated hydrochloric acid $(25 \mathrm{ml}, 300 \mathrm{mmol})$ and aromatic polyamide $7(300 \mathrm{mg})$ were placed in a flask equipped with reflux condenser. The mixture was stirred for 8 hours under refluxing condition. Then the solution was cooled and dried in vacuo. The obtained crystalline compound was determined to be $\mathbf{3}$ (320 $\mathrm{mg}, 97.0 \%)$.

\section{X-ray crystallography}

Crystallographic data (without structure factors) for the photodimer 3 have been deposited with Cambridge Crystallographic Data Centre. These data can be obtained free of charge from The 
Cambridge Crystallographic Data Centre via www.ccdc.cam.ac.uk/data_request/cif, by e-mailing data_request@ccdc.cam.ac.uk, or by contacting CCDC 12 Union Road, Cambridge CB2 1EZ, UK; fax: +44 1223336033 .

A single crystal was obtained from dispersion liquid of crude 4,4'-diamino-dimethyltruxillate dihydrochloride in conc. $\mathrm{HCl}$ aqueous, refluxed for $10 \mathrm{~min}$ and then cooled to room temperature. Pure sample was obtained as needle crystal. Single crystal X-ray crystallographic diffraction data were collected a Bruker Smart APEX II CCD area-detector diffractometer, with Mo Ka radiation source $(\lambda=0.71073 \AA)$ at $296 \mathrm{~K}$. The crystal structures were solved by the directed method with SHELXS-97 program. The full matrix least squares procedures using SHELXL-97 on $F^{2}$ anisotropic for all non-hydrogen atom was used to refine the crystal structures (Sheldrick, 1997). Hydrogen atoms were placed in their calculated positions and refined following the riding model. Crystal data: $0.50 \times 0.10 \times 0.06 \mathrm{~mm}, \mathrm{C}_{18} \mathrm{H}_{20} \mathrm{Cl}_{2} \mathrm{~N}_{2} \mathrm{O}_{4}$, pale yellow, $f w=399.26$, triclinic, $\mathrm{P} 2(1) \backslash \mathrm{n}, a$ $=5.6577(11) \AA, b=7.6483(16) \AA, c=12.102(3) \AA, \alpha=105.024(12)^{\circ}, \beta=94.685(12)^{\circ}, \gamma=$ $105.769(8)^{\circ}, V=480.16(19) \AA^{3}, Z=1,1.381 \mathrm{mg} / \mathrm{m}^{3}, \mathrm{~T}=296(2) \mathrm{K}, \mathrm{R}_{1}(\mathrm{I}>2 \sigma(\mathrm{I}))=0.0442, \omega \mathrm{R} 2($ all data) $=0.1250, \mathrm{GOF}=1.019$ 


\section{References}

(1) Suvannasara, P.; Tateyama, S.; Miyasato, A.; Matsumura, K.; Shimoda, T.; Ito, T.; Yamagata, Y.; Fujita, T.; Takaya, N.; Kaneko, T. Macromolecules 2014, 47, 1586-1593.

(2) Huang, J.; Gu, M.; Lai, Z.; Fan, B.; Shi, K.; Zhou, Y.; Yu, J.; Chen, Z. Plant Physiol. 2010, $153,1526-1538$.

(3) Sato, K.; Shin-I, T.; Seki, M.; Shinozaki, K.; Yoshida, H.; Takeda, K.; Yamazaki, Y.; Conte, M.; Kohara, Y. DNA Res. 2009, 16, 81-89.

(4) Zhu, L.; Cui, W.; Fang, Y.; Liu, Y.; Gao, X.; Zhou, Z. Biotechnol. Lett. 2013, 35, 751-756.

(5) Baba, T.; Ara, T.; Hasegawa, M.; Takai, Y.; Okumura, Y.; Baba, M.; Datsenko, K. A.; Tomita, M.; Wanner, B. L.; Mori, H. Mol. Syst. Biol. 2006, 2.

(6) Fujita, T.; Nguyen, H.; Ito, T.; Zhou, S.; Osada, L.; Tateyama, S.; Kaneko, T.; Takaya, N. Appl. Microbiol. Biotechnol. 2013, 97, 8887-8894.

(7) Zucker, M. Plant Physiol. 1965, 40, 779-784. 
Table S1. Production of 4 Aphe by various $E$. coli transformants

\begin{tabular}{|c|c|c|c|}
\hline \multirow[b]{2}{*}{ E. coli strain } & \multicolumn{2}{|c|}{ Expression genes and vectors } & \multirow[b]{2}{*}{$\begin{array}{l}\text { 4APhe } \\
\text { production } \\
\left(\mathrm{g} \mathrm{l}^{-1}\right)\end{array}$} \\
\hline & PapA/Plasmid & $\begin{array}{l}\text { PapB and PapC } \\
\text { /Plasmid }\end{array}$ & \\
\hline \multirow[t]{8}{*}{ BL21-Gold (DE3) } & $E c \mathrm{PabAB} / \mathrm{pET}$ & $S p \mathrm{PapBC} / \mathrm{pRSF}$ & 0.03 \\
\hline & $S v P a p A / p E T$ & $S p \mathrm{PapBC} / \mathrm{pRSF}$ & 0.03 \\
\hline & $E c \mathrm{PabAB} / \mathrm{pRSF}$ & $S p P a p B C / p E T$ & $<0.001$ \\
\hline & $S v P a p A / p R S F$ & $S p \mathrm{PapBC} / \mathrm{pET}$ & $<0.001$ \\
\hline & $E c \mathrm{PabAB} / \mathrm{pET}$ & $S v \mathrm{PapBC} / \mathrm{pRSF}$ & $<0.001$ \\
\hline & $S v P a p A / p E T$ & $S v \mathrm{PapBC} / \mathrm{pRSF}$ & $<0.001$ \\
\hline & $E c \mathrm{PabAB} / \mathrm{pRSF}$ & $S v \mathrm{PapBC} / \mathrm{pET}$ & $<0.001$ \\
\hline & SvPapA/pRSF & $S v$ PapBC/pET & $<0.001$ \\
\hline \multirow[t]{2}{*}{ BL21-Gold (DE3)pLysS } & $E c \mathrm{PabAB} / \mathrm{pET}$ & $S p$ PapBC/pRSF & $<0.01$ \\
\hline & $S v \mathrm{PapA} / \mathrm{pET}$ & $S p$ PapBC/pRSF & $<0.01$ \\
\hline \multirow[t]{2}{*}{ BL21-CodonPlus (DE3)-RIPL } & $E c \mathrm{PabAB} / \mathrm{pET}$ & $S p \mathrm{PapBC} / \mathrm{pRSF}$ & $<0.01$ \\
\hline & $S v P a p A / p E T$ & $S p \mathrm{PapBC} / \mathrm{pRSF}$ & $<0.01$ \\
\hline \multirow[t]{2}{*}{ BL21-CodonPlus (DE3)-RIL } & $E c \mathrm{PabAB} / \mathrm{pET}$ & $S p \mathrm{PapBC} / \mathrm{pRSF}$ & $<0.01$ \\
\hline & $S v P a p A / p E T$ & $S p \mathrm{PapBC} / \mathrm{pRSF}$ & $<0.01$ \\
\hline \multirow[t]{2}{*}{ HMS174 (DE3) } & $E c \mathrm{PabAB} / \mathrm{pET}$ & $S p \mathrm{PapBC} / \mathrm{pRSF}$ & $<0.001$ \\
\hline & $S v P a p A / p E T$ & $S p \mathrm{PapBC} / \mathrm{pRSF}$ & $<0.001$ \\
\hline \multirow[t]{2}{*}{ HMS174 (DE3)pLysS } & $E c \mathrm{PabAB} / \mathrm{pET}$ & $S p \mathrm{PapBC} / \mathrm{pRSF}$ & $<0.001$ \\
\hline & $S v P a p A / p E T$ & $S p \mathrm{PapBC} / \mathrm{pRSF}$ & $<0.001$ \\
\hline \multirow[t]{2}{*}{ NST37 (DE3) } & $E c \mathrm{PabAB} / \mathrm{pET}$ & $S p \mathrm{PapBC} / \mathrm{pRSF}$ & 0.05 \\
\hline & $S v P a p A / p E T$ & $S p \mathrm{PapBC} / \mathrm{pRSF}$ & 0.10 \\
\hline
\end{tabular}

Cells were cultured in $10 \mathrm{~mL}$ of $\mathrm{M} 9$ medium containing $1 \%$ glucose in $50-\mathrm{mL}$ test tubes at $30^{\circ} \mathrm{C}$ for $36 \mathrm{~h}$. Combinations of genes encoding PapABC were expressed using vectors pETduetl or pRSFduet1. Ec, E. coli; Sv, S. venezuelae; Sp, S. pristinaespiralis. pET, pETduet1; pRSF, pRSFduet1. Data are shown as means of three experiments. Standard errors are $<20 \%$. 
Table S2. Optimization of culture medium and IPTG concentration for 4APhe production

\begin{tabular}{lllll}
\hline $\begin{array}{l}\text { Temperature } \\
\left({ }^{\circ} \mathrm{C}\right)\end{array}$ & \multicolumn{2}{l}{ Nutrients $(\mathrm{g} / \mathrm{L})$} & $\begin{array}{l}\text { IPTG } \\
(\mathrm{mM})\end{array}$ & 4APhe $(\mathrm{g} / \mathrm{L})$ \\
\cline { 2 - 4 } 37 & Yeast extract & Tryptone & 0.1 & 0.2 \\
37 & 0 & 0 & 0.5 & 0.2 \\
37 & 0 & 0 & 1.0 & 0.1 \\
30 & 0 & 0 & 0.1 & 0.4 \\
30 & 0 & 0 & 0.5 & 0.1 \\
30 & 0 & 0 & 1.0 & 0.1 \\
30 & 0 & 0 & 0.1 & 0.6 \\
30 & 1.0 & 2.0 & 0.5 & 0.3 \\
30 & 1.0 & 2.0 & 0.1 & 0.2 \\
30 & 2.5 & 5.0 & 0.5 & 0.2 \\
\hline
\end{tabular}

Escherichia coli NST37(DE3) cells harboring pET-svPapA and pRSF-spPapBC were cultured in $100 \mathrm{~mL}$ of M9 medium containing 1\% glucose and indicated amounts of nutrients in 500-mL flasks at $30^{\circ} \mathrm{C}$ for $36 \mathrm{~h}$. Data are means of three experiments. Standard errors are $<20 \%$. 
Table S3. Effect of pheA gene disruption on 4APhe and phenylalanine production

\begin{tabular}{|c|c|c|}
\hline E. coli strains & 4APhe $(\mathrm{g} / \mathrm{L})$ & Phe $(g / L)$ \\
\hline NST37(DE3)/papABC & 0.6 & 0.6 \\
\hline NST37(DE3)/ApheLA/papABC & 0.9 & $<0.1$ \\
\hline NST37(DE3)/ $4 p h e L A /$ papABC/tyrB & 1.1 & $<0.1$ \\
\hline NST37(DE3)/ApheLA/papABC/tyrB/aspC & 0.9 & $<0.1$ \\
\hline
\end{tabular}

Strains harboring pET-svPapA and pRSF-spPapBC were cultured in $100 \mathrm{~mL}$ of M9 medium containing $1 \%$ glucose in $500-\mathrm{mL}$ flasks at $30^{\circ} \mathrm{C}$ for $36 \mathrm{~h}$. Data are means of three experiments. Standard errors are $<20 \%$. 
Table S4. Phenylalanine and 4APhe ammonia lyase activities in cell-free extracts of $E$. coli

\begin{tabular}{lll} 
Specific activity $(\mu \mathrm{mol} / \mathrm{min} / \mathrm{mg})$ & \\
\cline { 2 - 3 } Enzyme & $\mathrm{PAL}$ & 4APhe ammonia lyase \\
\hline AtPAL4 & $3.3 \times 10^{-5}(100)$ & $1.0 \times 10^{-7}(0.3)$ \\
HvPAL & $2.3 \times 10^{-6}(100)$ & $2.6 \times 10^{-7}(8.8)$ \\
RgPAL & $6.4 \times 10^{-5}(100)$ & $1.2 \times 10^{-6}(1.9)$ \\
\hline
\end{tabular}

Enzymes were produced in E. coli BL21(DE3). Relative activities are shown in parenthesis. Data are means of three experiments. Standard errors are $<10 \%$. 
Table S5. Primers used in this study

\begin{tabular}{|c|c|c|}
\hline Name & Nucleotide sequence 5' -3 ' & Used to generate \\
\hline SvpAF & 5'-gacacactatgcgcacgcttctgatcgac-3' & S. venezuelae papA \\
\hline SvpAR & 5'-gacgatatcatcgggcgeccgccacggc-3' & S. venezuelae papA \\
\hline SvpBF & $5^{\prime}$-gagccatgggcaccgagcagaacgagctg $-3^{\prime}$ & S. venezuelae papB \\
\hline SvpBR & $5^{\prime}$-cagaagcttcaccgecggtcctcggecgtc $-3^{\prime}$ & S. venezuelae papB \\
\hline SvpCF & $5^{\prime}$-cagagacatatgagcggcttccccegcag $-3^{\prime}$ & S. venezuelae papC \\
\hline SvpCR & $5^{\prime}$-gactcgagtcatcggtccttctcgecttcg $-3^{\prime}$ & S. venezuelae papC \\
\hline SppBF & 5'-cagccatgggcaccecgeccgecatcccc -3' & S. pristinaespiralis papB \\
\hline SppBR & $5^{\prime}$ - cagaagcttcacgacacggecceccgeg- $3^{\prime}$ & S. pristinaespiralis papB \\
\hline $\mathrm{SppCF}$ & $5^{\prime}$-cagagacatatgaggggtggttcggtgttcg $-3^{\prime}$ & S. pristinaespiralis papC \\
\hline SppCR & $5^{\prime}$-cagatatcagtgcagggcggtgaacatc $-3^{\prime}$ & S. pristinaespiralis papC \\
\hline EpaAF & $5^{\prime}$-cagccatgggcatcctgcttatagataac $-3^{\prime}$ & E. coli pabA \\
\hline EpaAR & $5^{\prime}$-gaaacgtttcagcgatgcaggaaattagc $-3^{\prime}$ & E. coli pabA \\
\hline EpaBF & $5^{\prime}$-cagagacatatgaagacgttatctccegc $-3^{\prime}$ & E. coli pabB \\
\hline EpaBR & $5^{\prime}$-cactcgagttacttctccagttgettcagg $-3^{\prime}$ & E. coli pabB \\
\hline TyBF & $5^{\prime}$-gagccatgggctttcaaaaagttgacgcc-3' & E. coli tyr $B$ \\
\hline TyBR & $5^{\prime}$-caggatccttacatcaccgcagcaaacg-3' & E. coli tyr $B$ \\
\hline $\mathrm{AsCF}$ & $5^{\prime}$-gaacctccatatgtttgagaacattacc-3' & E. coli aspC \\
\hline $\mathrm{AsCR}$ & $5^{\prime}$-ccctcgagttacagcactgecacaatc $-3^{\prime}$ & E. coli aspC \\
\hline AtPF & $5^{\prime}$-cagagatctatggagctatgcaatcaaaac-3' & A. thaliana pal4 \\
\hline AtPR & 5'-gacgcatgctcaacagattgaaaccggagctc-3' & A. thaliana pal4 \\
\hline $\mathrm{HvPF}$ & $5^{\prime}$ - cagagacatatggagtgcgataacgggcac-3' & H. vulgare pal \\
\hline HvPR & $5^{\prime}$ - gacgatatcagcagataggcaggggctc-3' & H. vulgare pal \\
\hline
\end{tabular}

Restriction sites are underlined.

Table S6. Product distribution on UV irradiation of 4ACA derivatives 


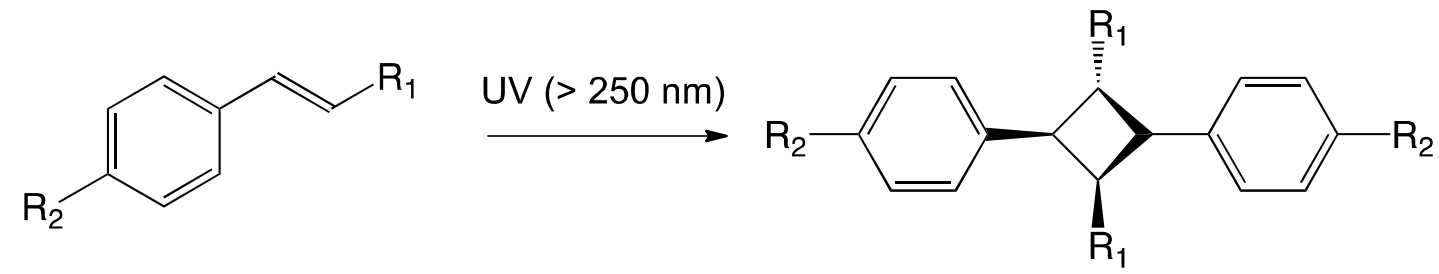

\begin{tabular}{|c|c|c|c|c|c|c|}
\hline \multirow{2}{*}{ Compounds } & \multirow{2}{*}{$\begin{array}{l}\text { Time } \\
\text { (h) }\end{array}$} & \multirow{2}{*}{ Solvents } & \multicolumn{3}{|c|}{ Conversion $(\%)$} & \multirow{2}{*}{ Photodimers } \\
\hline & & & trans & cis & cyclobutane & \\
\hline \multirow{4}{*}{1} & 2 & Benzene & 0 & 0 & 100 & \multirow{4}{*}{3} \\
\hline & 2 & Dichloromethane & 0 & 0 & 100 & \\
\hline & 2 & Acetnitrile & 38 & 47 & 15 & \\
\hline & 2 & dimethylsulfoxide & 48 & 52 & 0 & \\
\hline 2 & 25 & Hexane & 0 & 0 & 100 & 4 \\
\hline
\end{tabular}



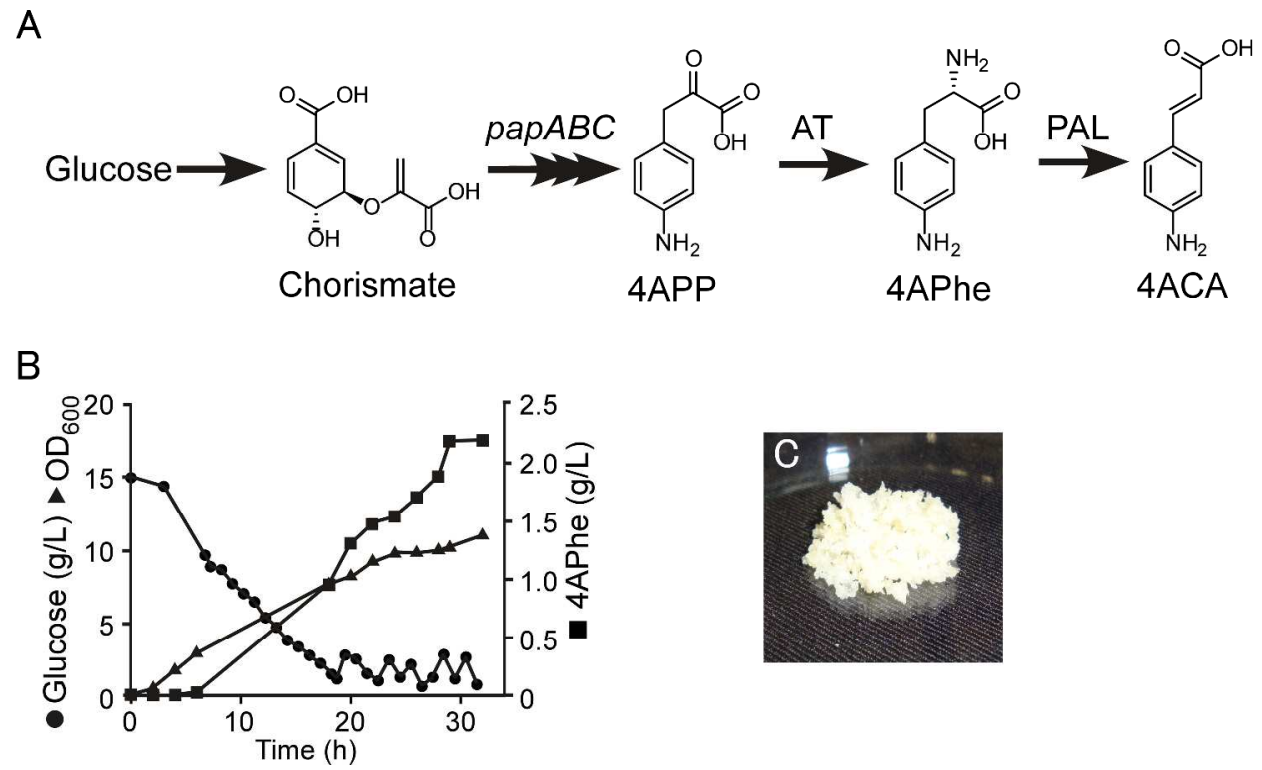

Figure S1. Biosynthesis of 4APhe by engineered E. coli. (A) Reactions involved in 4APhe and 4ACA production. (B) Fermentation of 4APhe. Escherichia coli strain $\mathrm{NST}(\mathrm{DE} 3) / \Delta p h e L A / \mathrm{papABC} / \mathrm{tyrB}$ was fed-batch cultured in $0.5 \mathrm{~L}$ of fermentation medium at $30^{\circ} \mathrm{C}$ and rotary shaken at $600 \mathrm{rpm}$. Culture $\mathrm{pH}$ was controlled at 7.0 with $10 \%$ ammonia. Glucose concentrations were monitored using BF-510 glucose sensor (Biott, Tokyo, Japan) and controlled at $\sim 4.0 \mathrm{~g} / \mathrm{L}$ with $50 \%$ glucose. (C) Purified 4APhe. 


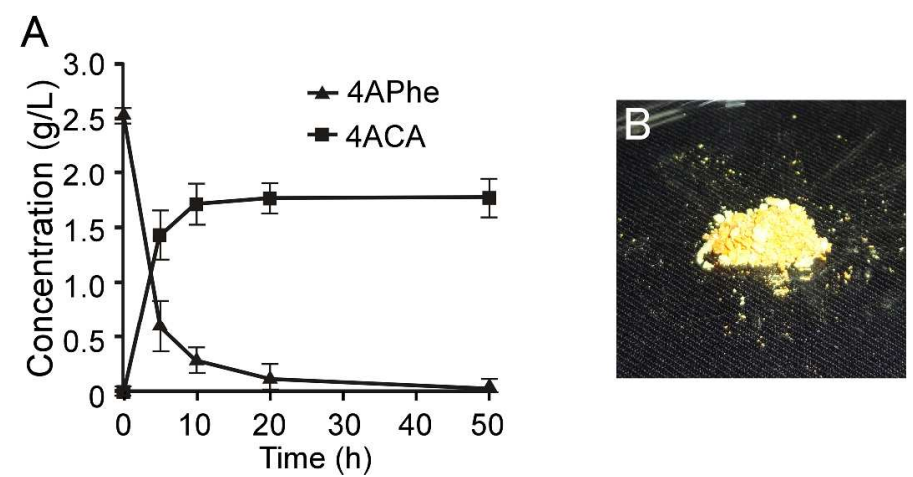

Figure S2. Biosynthesis of 4ACA by engineered E. coli. (A) Bioconversion of 4APhe to 4ACA. RgPAL-overexpressing E. coli cells were incubated in $100 \mathrm{mM}$ potassium phosphate buffer (pH 8.0) containing $4.0 \mathrm{~g} / \mathrm{L} 4 \mathrm{APhe}$ at $37^{\circ} \mathrm{C}$. (B) Purified 4ACA. 


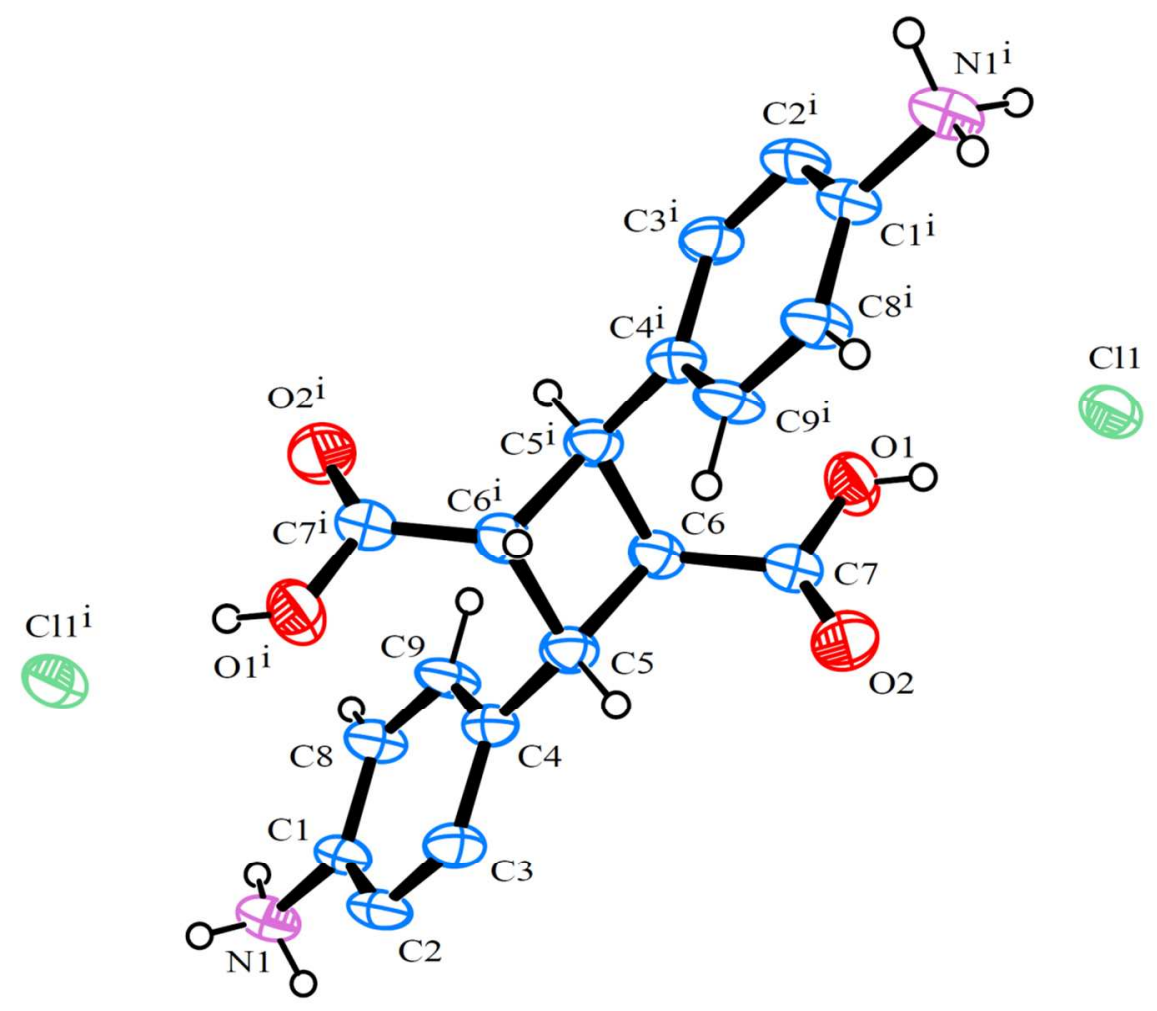

Figure S3. Structure of 4,4'-diamino- $\alpha$-truxillic acid dihydrochloride (3) confirmed by X-ray crystal analyses. 


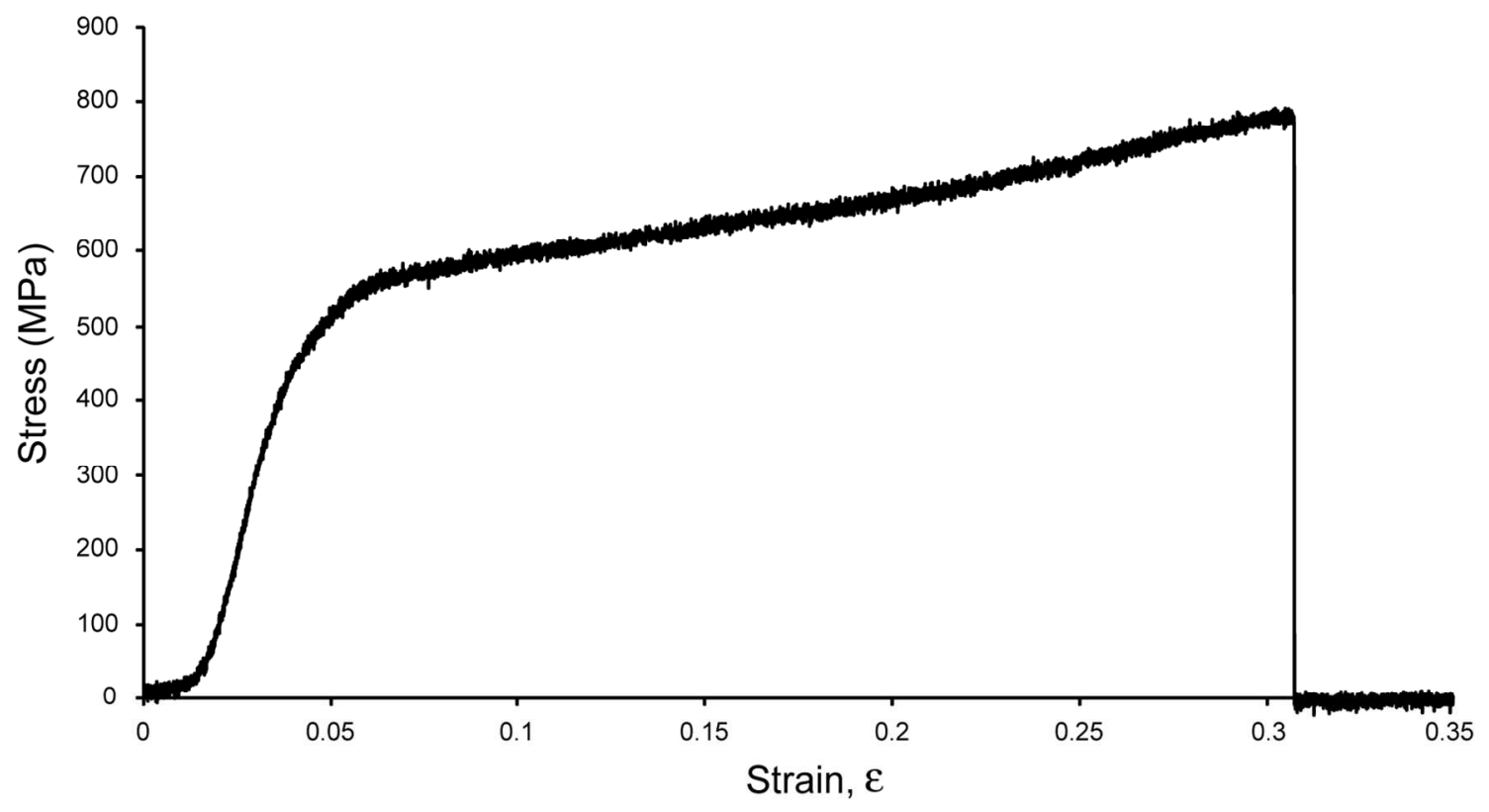

Figure S4-(a). Stress-strain curve of 10-C6. 


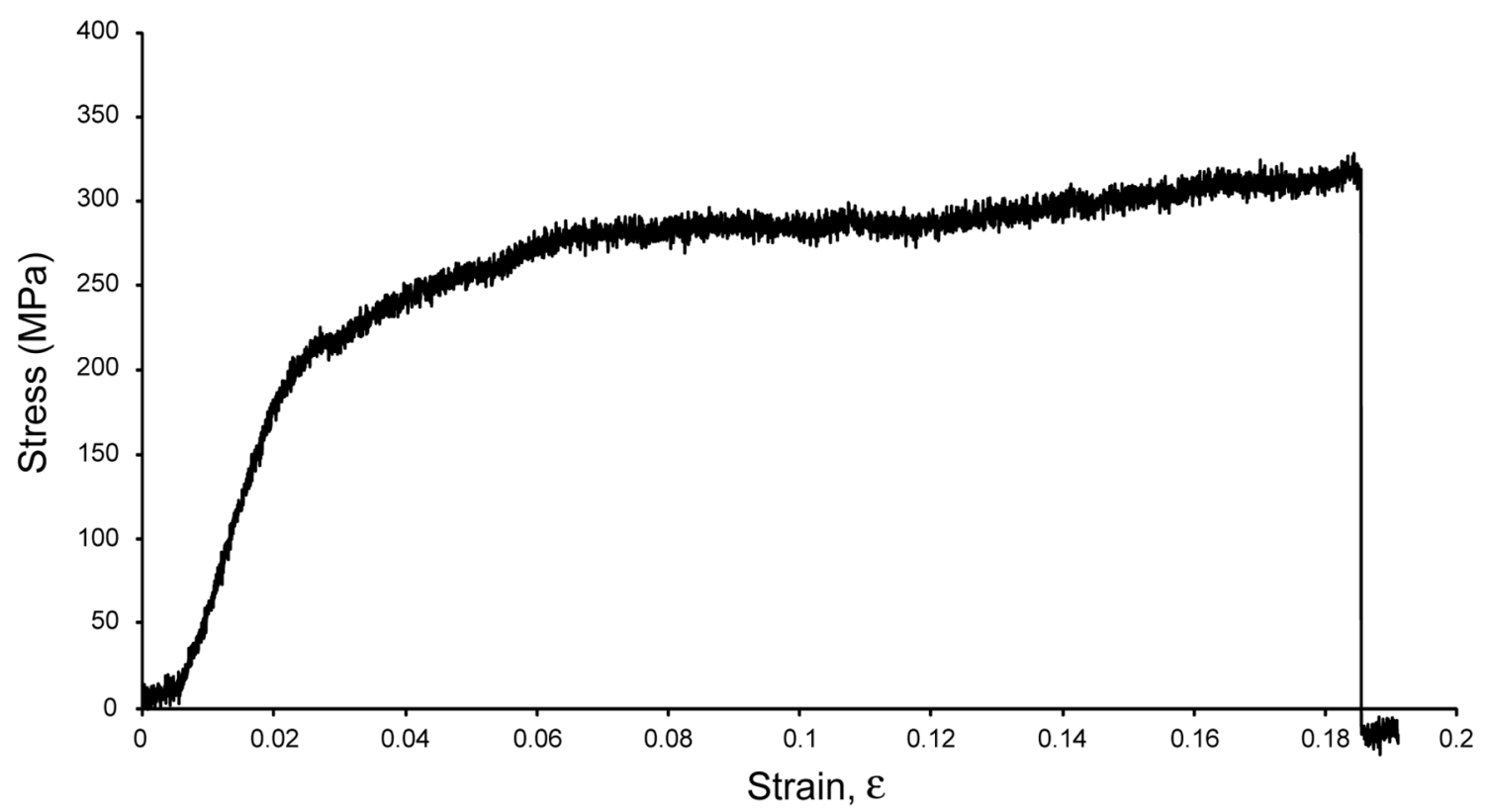

Figure S4-(b). Stress-strain curve of 10-C7. 


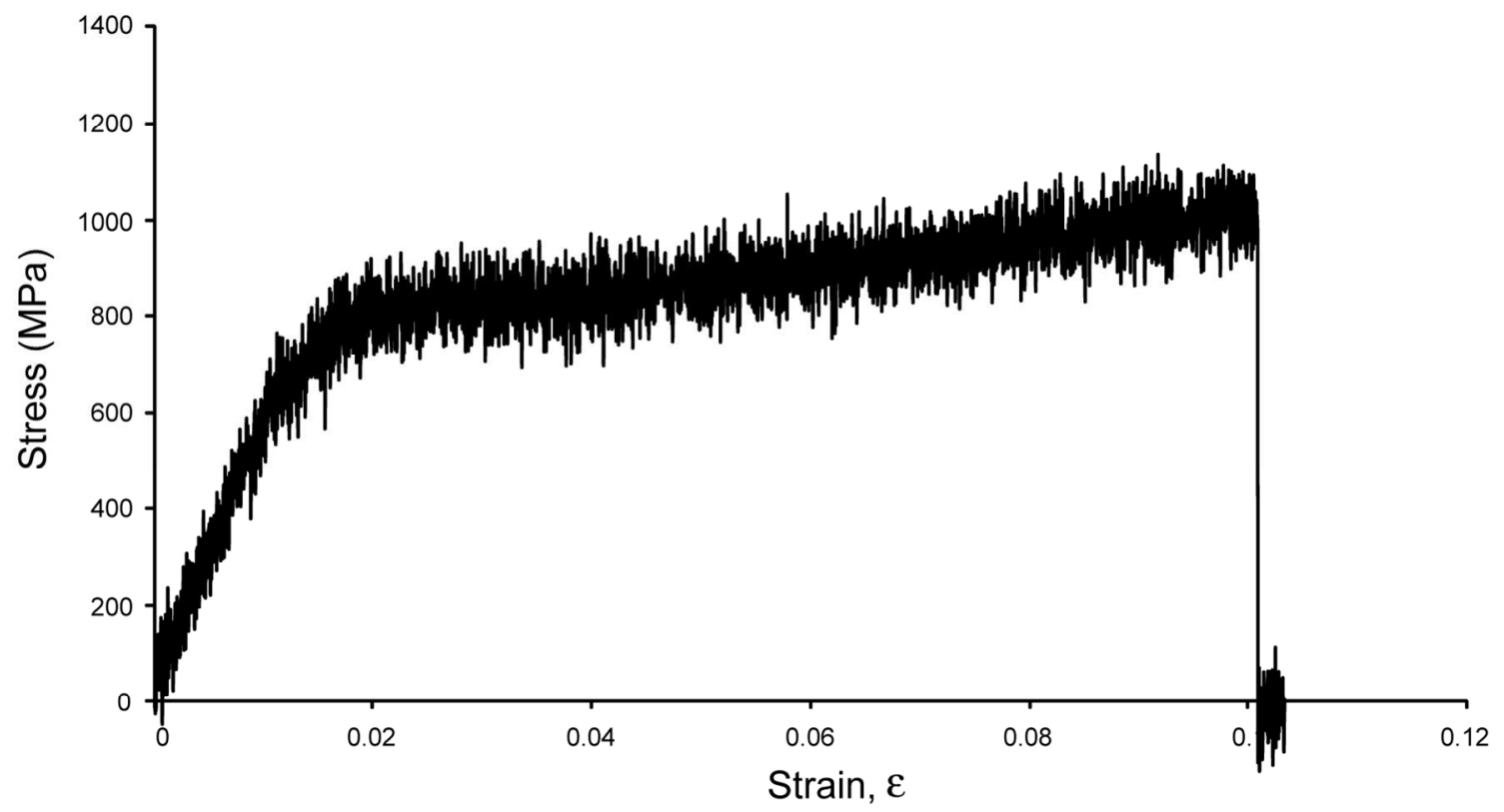

Figure S4-(c). Stress-strain curve of 10-C8. 


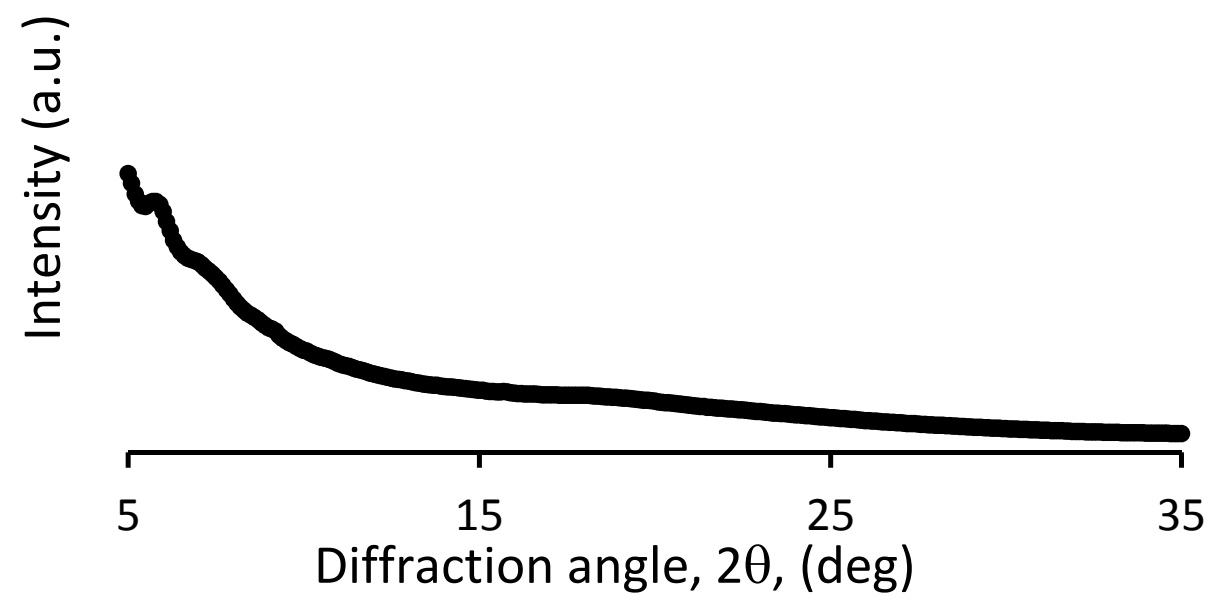

Figure S5. Wide angle X-ray diffraction diagram of polyamide 7. 


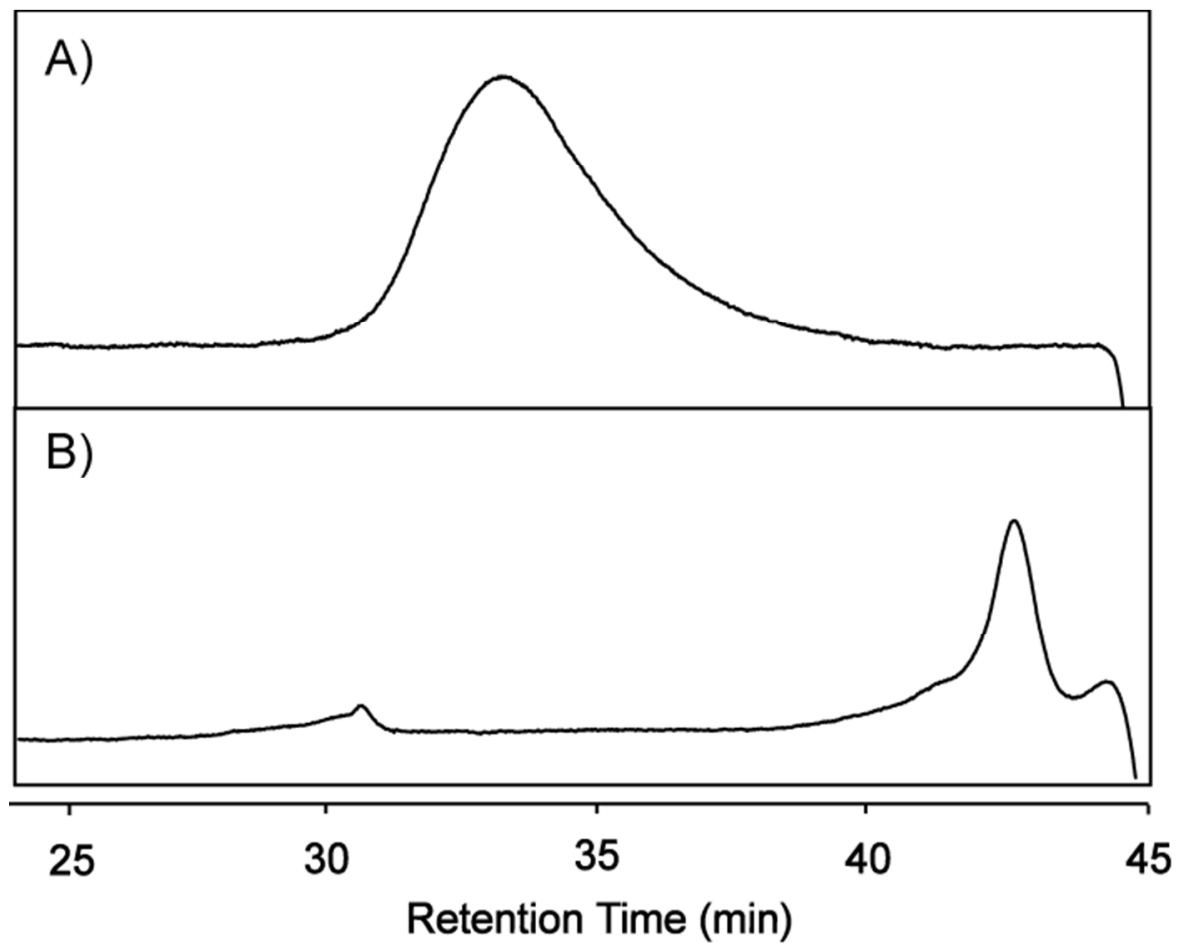

Figure S6. GPC chromatograms of photo-degraded 7. Before (A) and after (B) UV irradiation for $24 \mathrm{~h}$. 

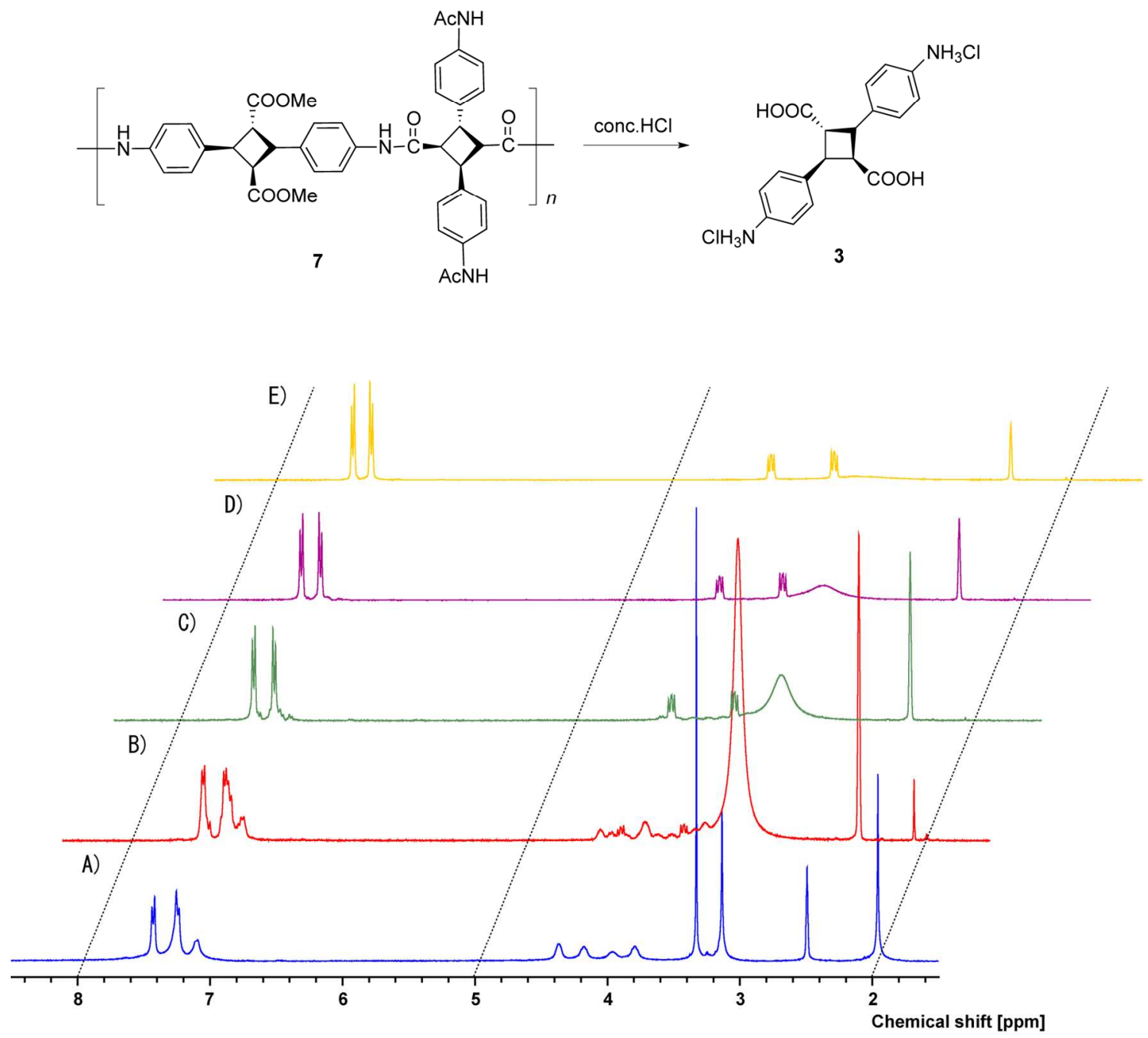

Figure S7. Hydrolysis reaction and ${ }^{1} \mathrm{H}$ NMR spectra of 7. Without (A) and with hydrolysis for $1 \mathrm{~h}$ (B), $2 \mathrm{~h}$ (C), $4 \mathrm{~h}$ (D) and $8 \mathrm{~h}$ (E) of hydrolysis. 


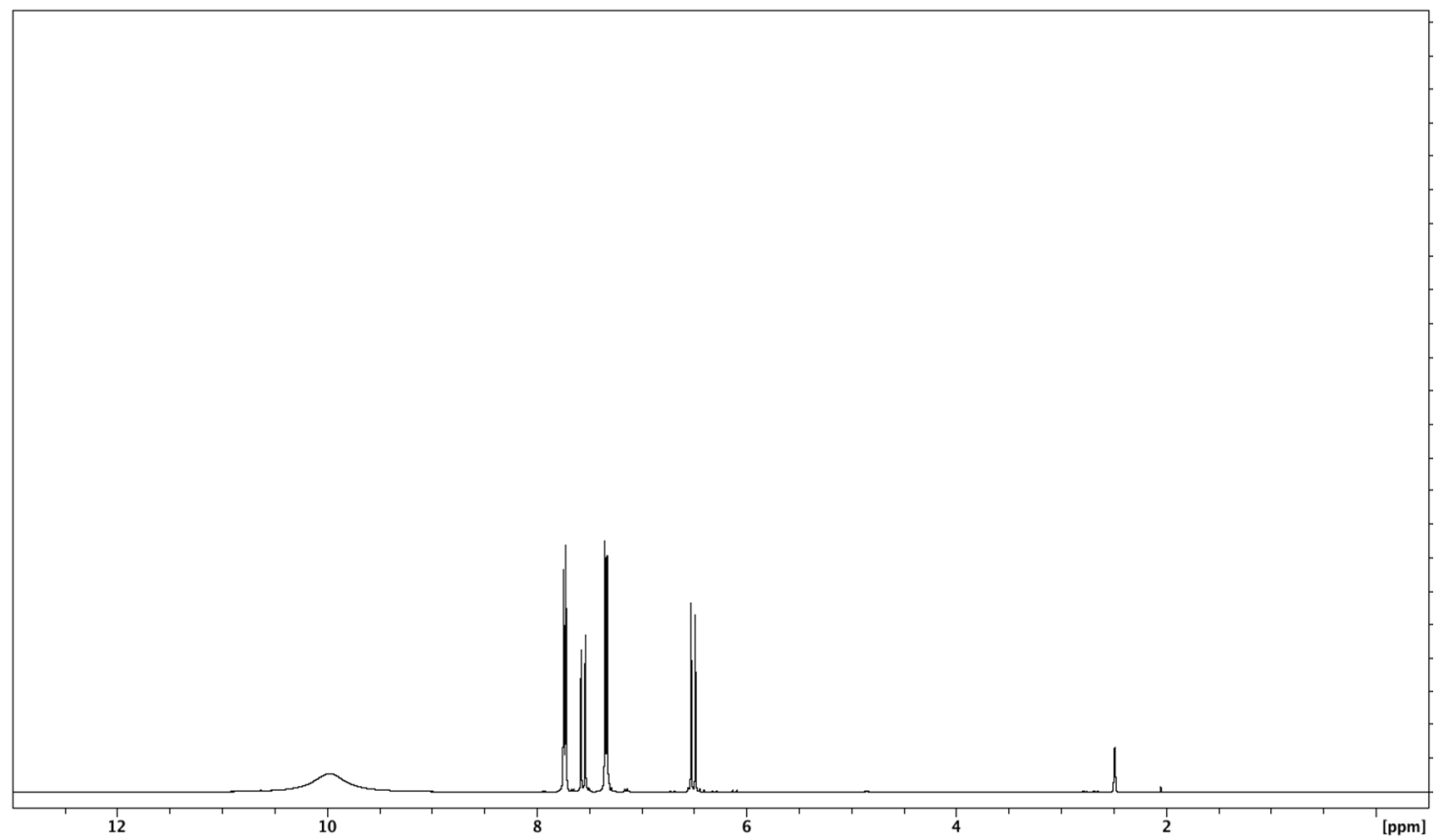

Figure S8-(a). $\quad{ }^{1}$ H NMR spectrum of 2.

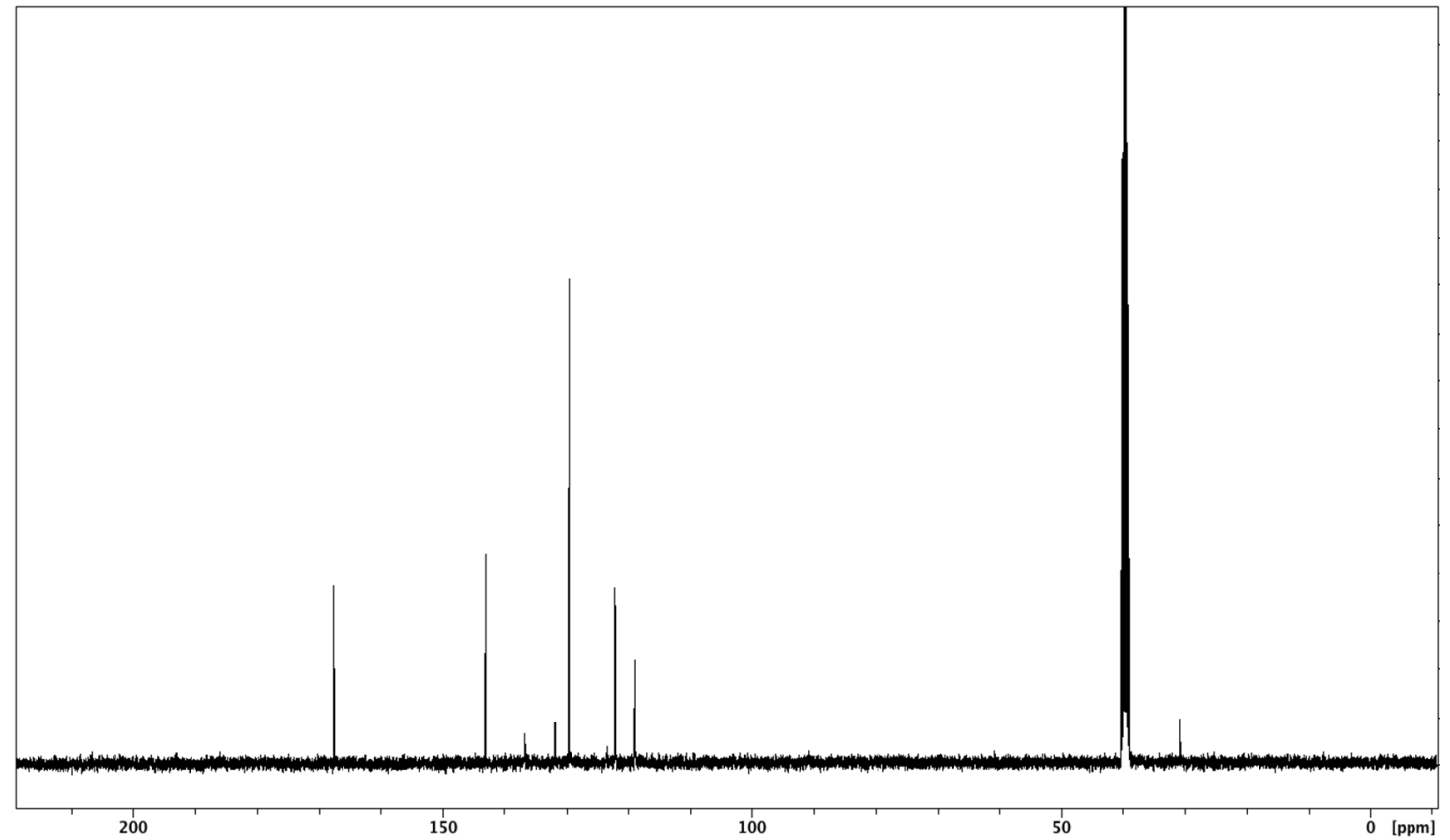

Figure S8-(b). ${ }^{13} \mathrm{C}$ NMR spectrum of 2. 


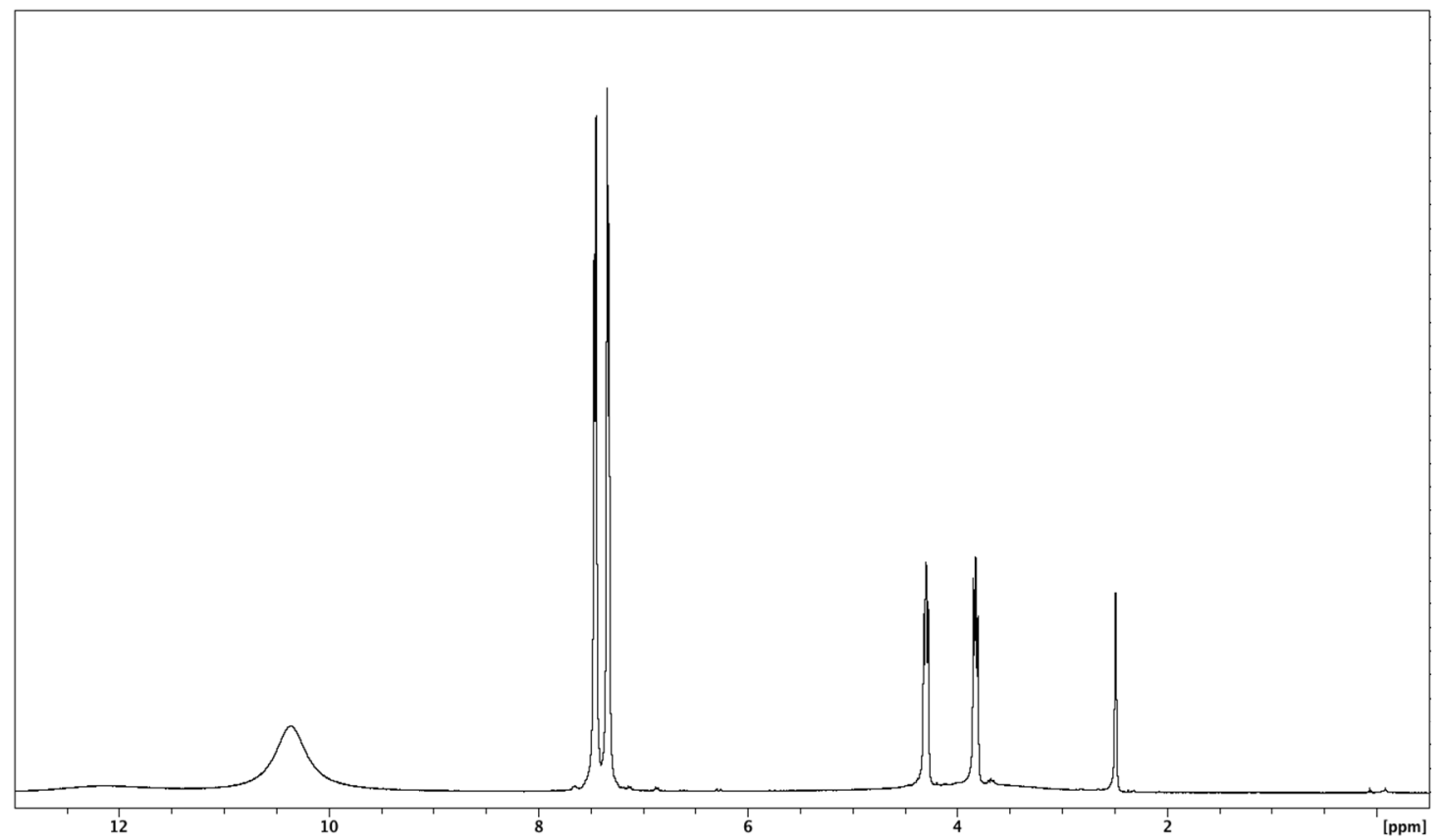

Figure S8-(c). $\quad{ }^{1} \mathrm{H}$ NMR spectrum of 3 .

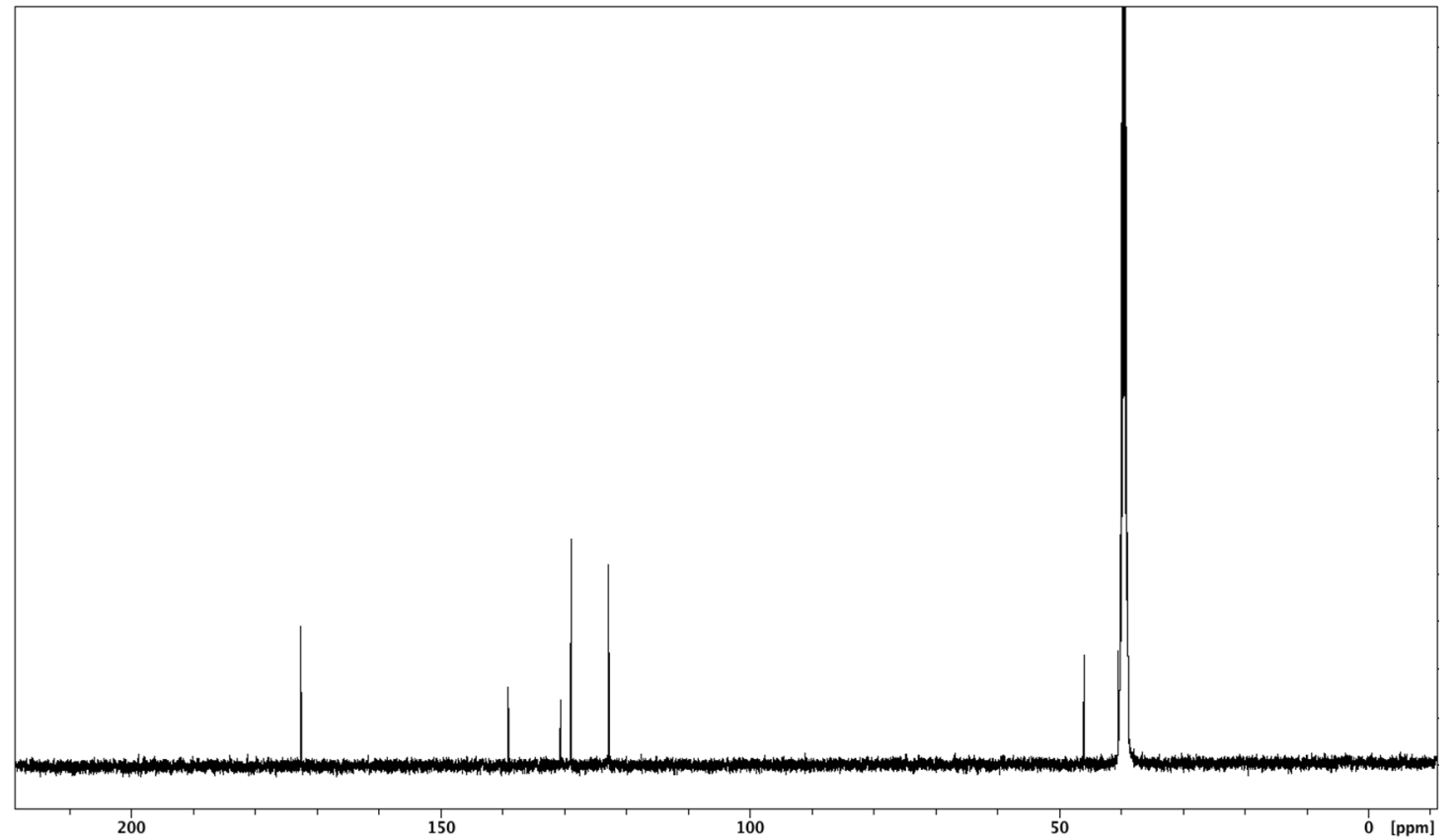

Figure S8-(d). ${ }^{13} \mathrm{C}$ NMR spectrum of 3. 


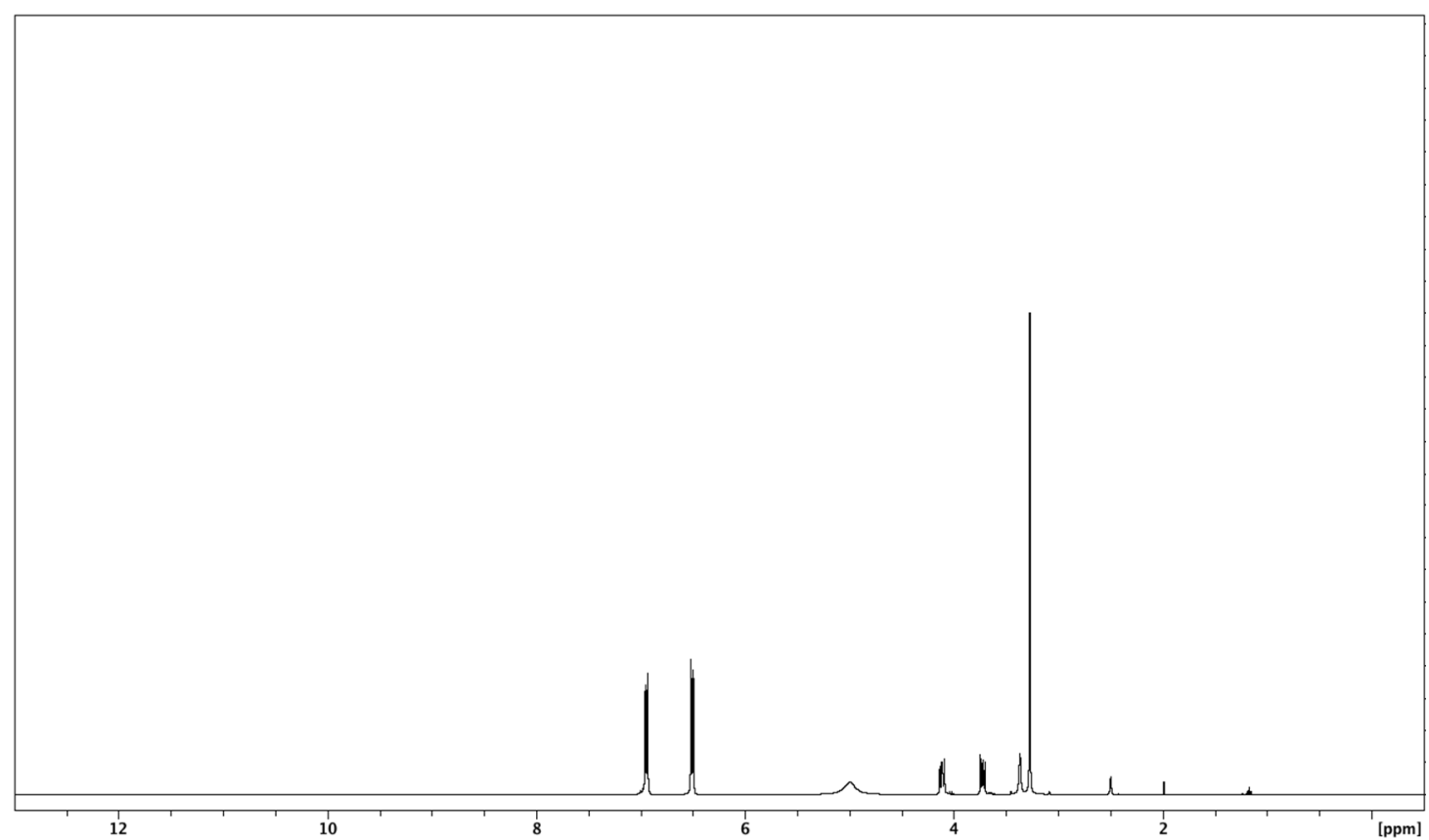

Figure S8-(e). $\quad{ }^{1} \mathrm{H}$ NMR spectrum of 4 .

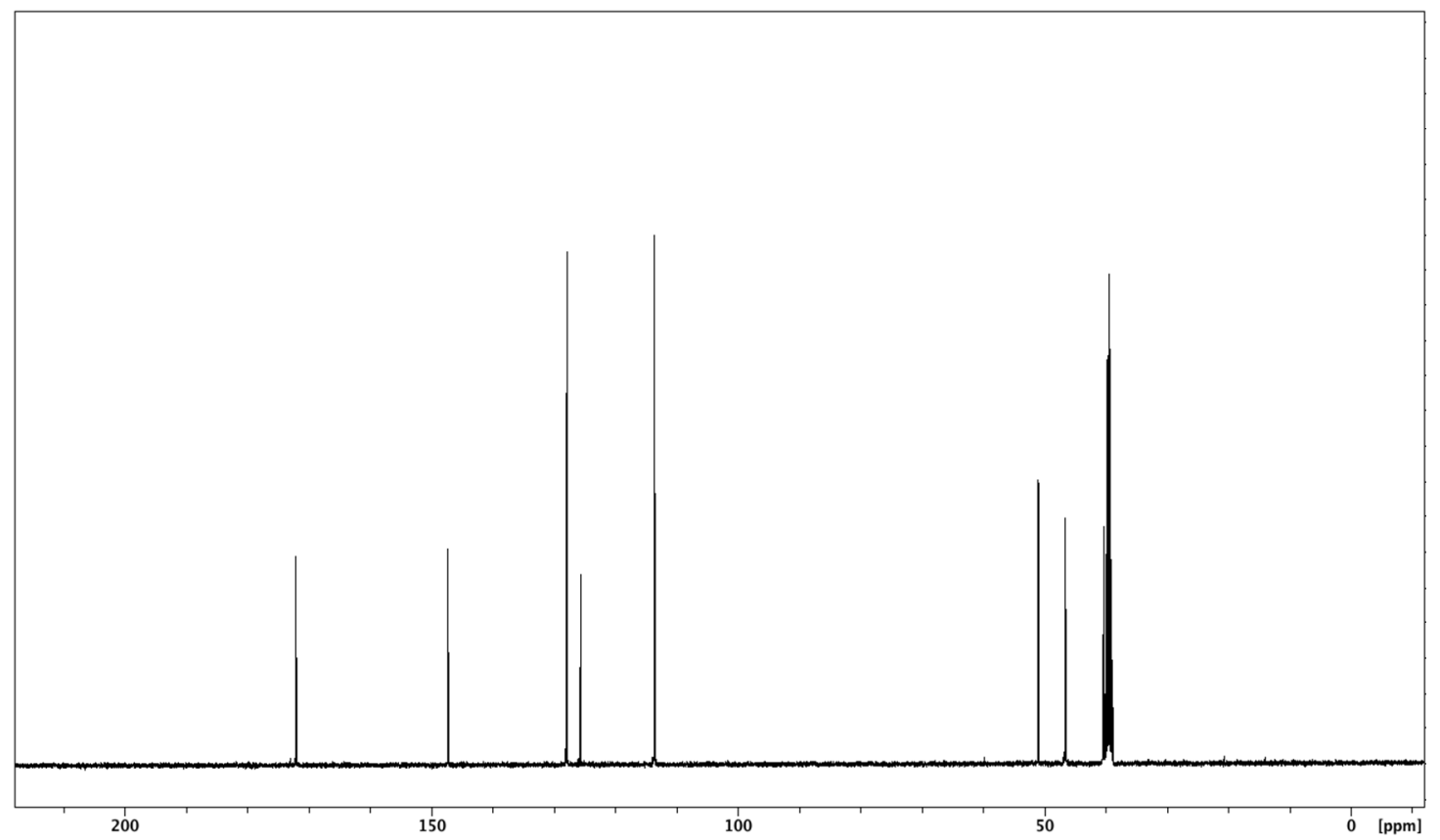

Figure S8-(f). $\quad{ }^{13} \mathrm{C}$ NMR spectrum of 4. 


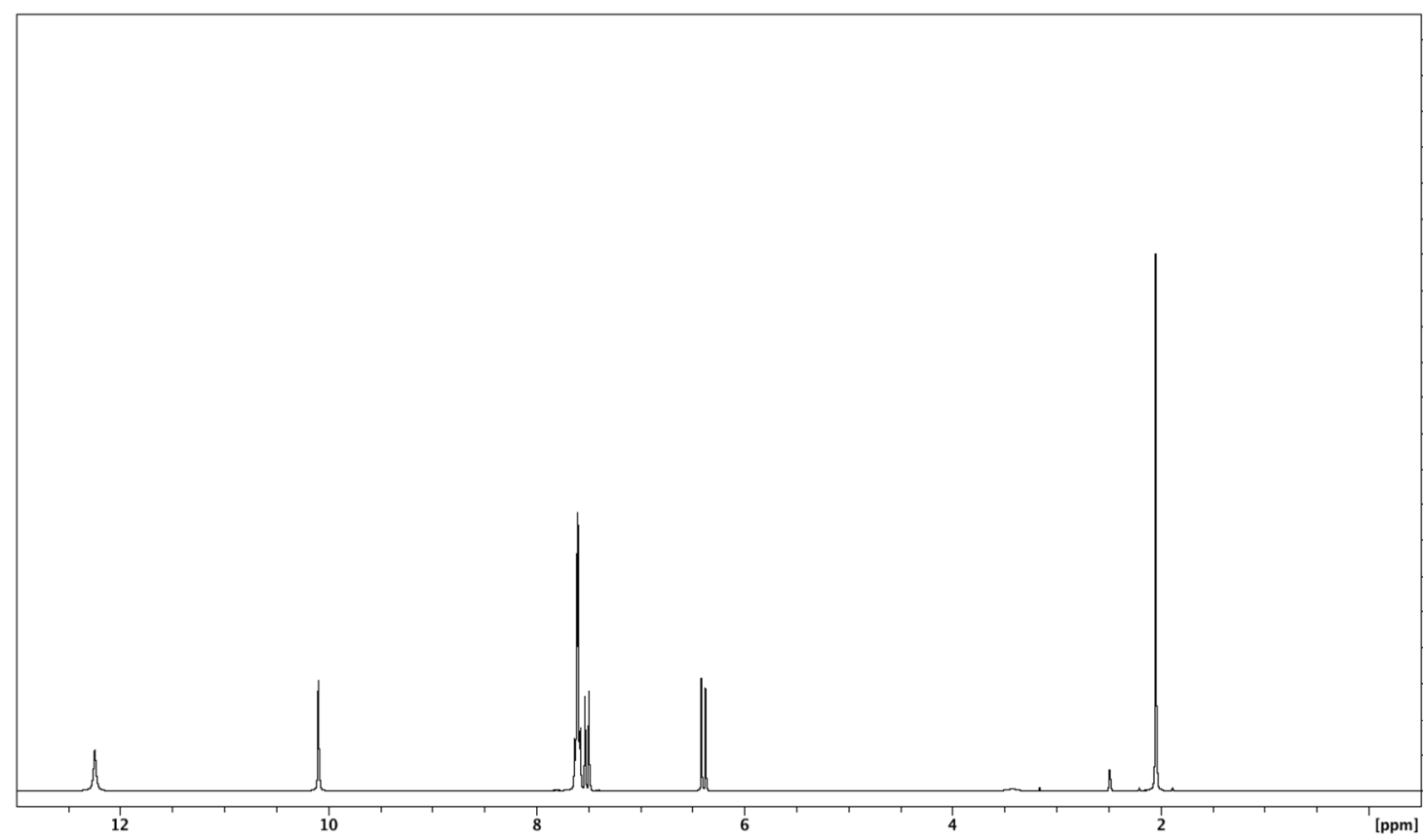

Figure S8-(g). $\quad{ }^{1} \mathrm{H}$ NMR spectrum of 5.

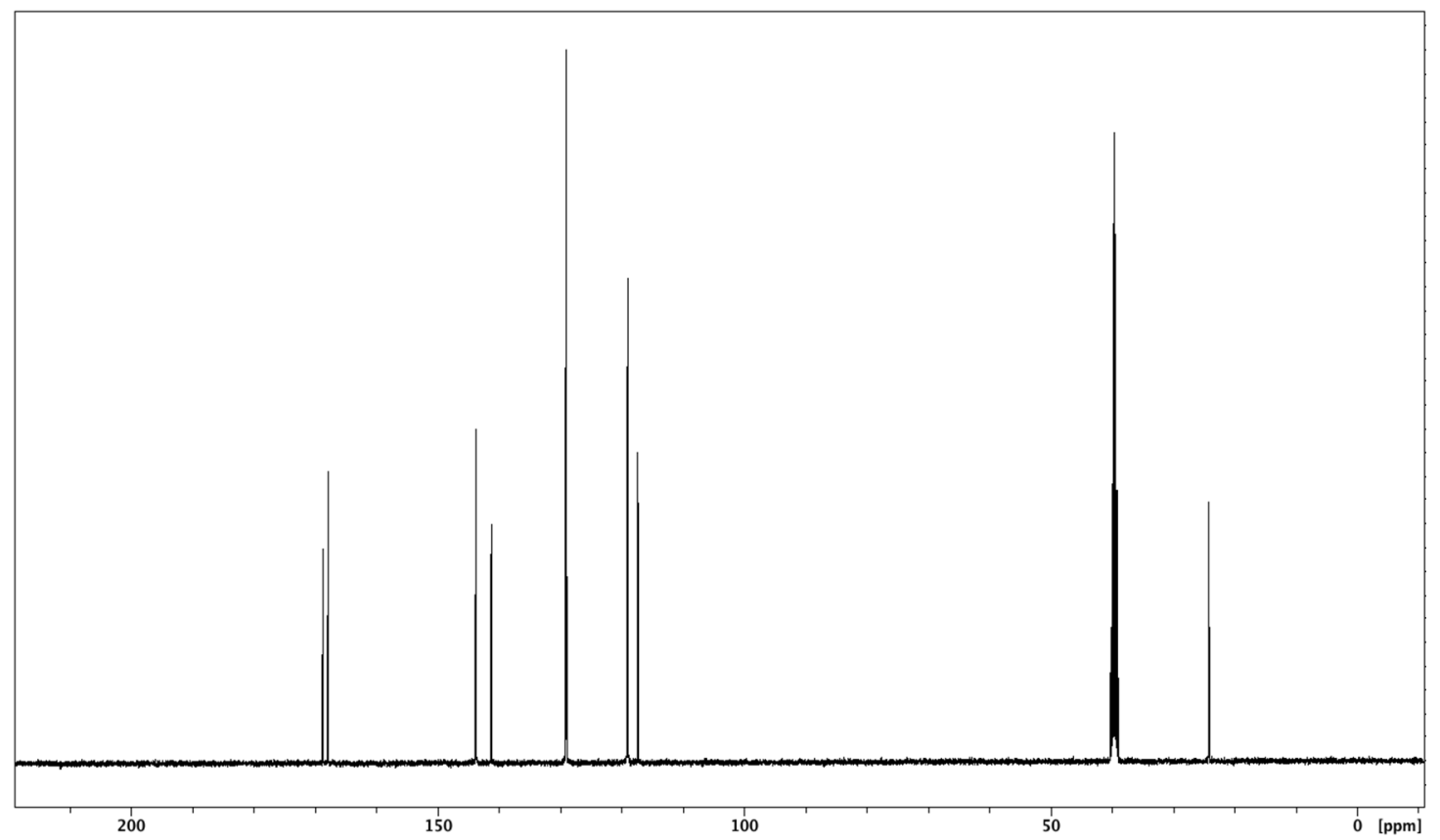

Figure S8-(h). ${ }^{13} \mathrm{C}$ NMR spectrum of $\mathbf{5}$. 


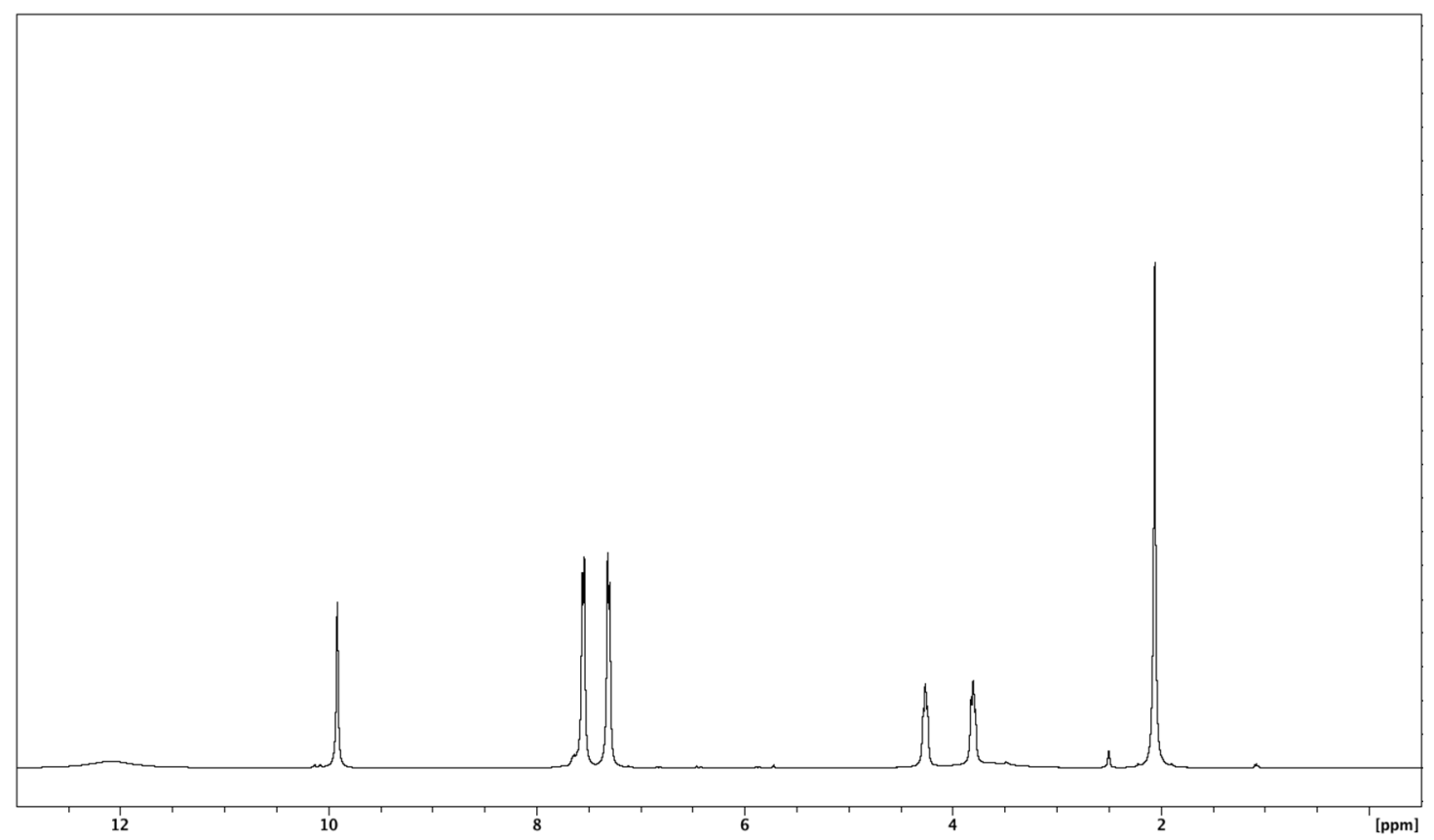

Figure S8-(i). $\quad{ }^{1} \mathrm{H}$ NMR spectrum of 6.

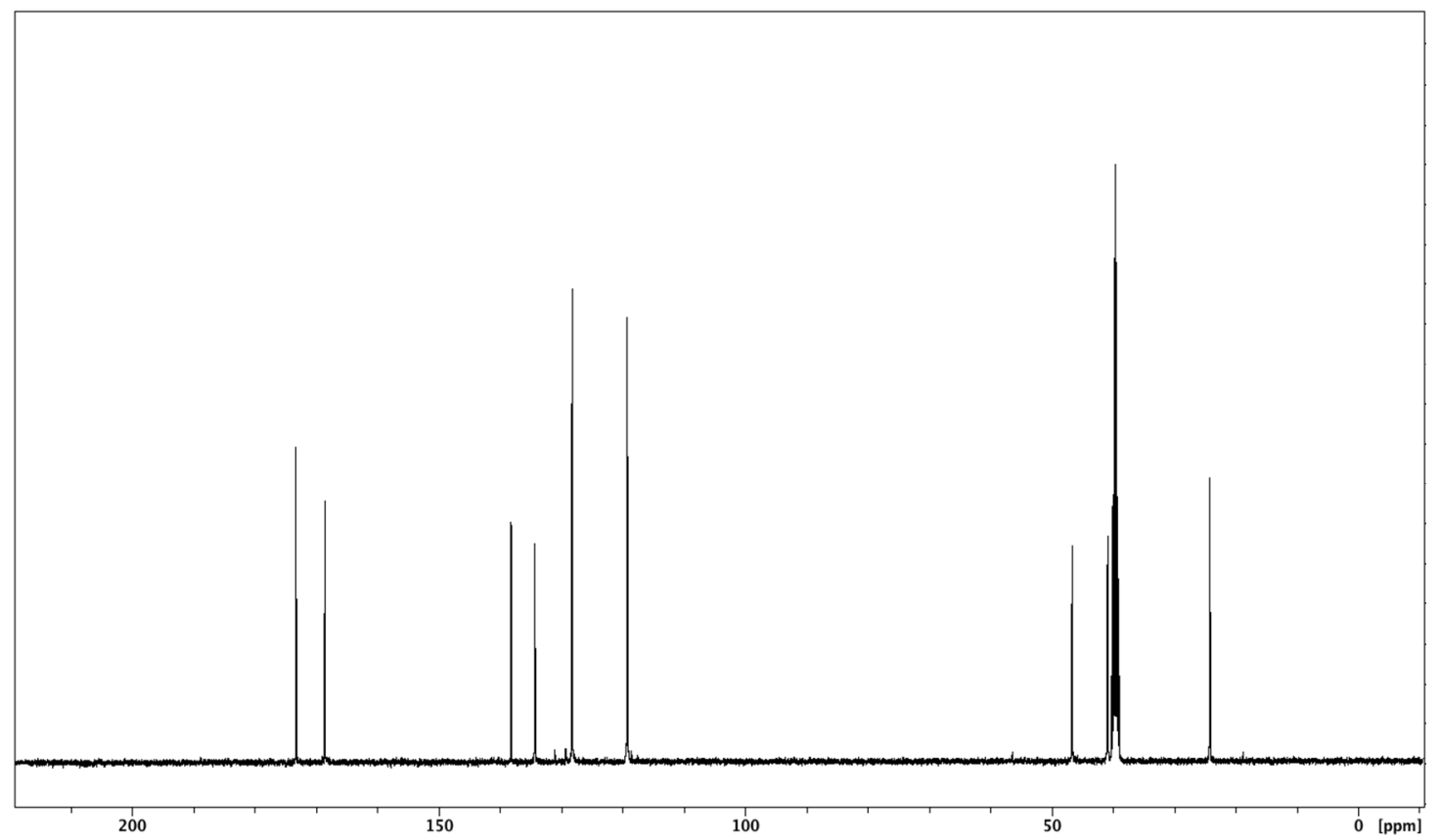

Figure S8-(j). $\quad{ }^{13} \mathrm{C}$ NMR spectrum of 6. 


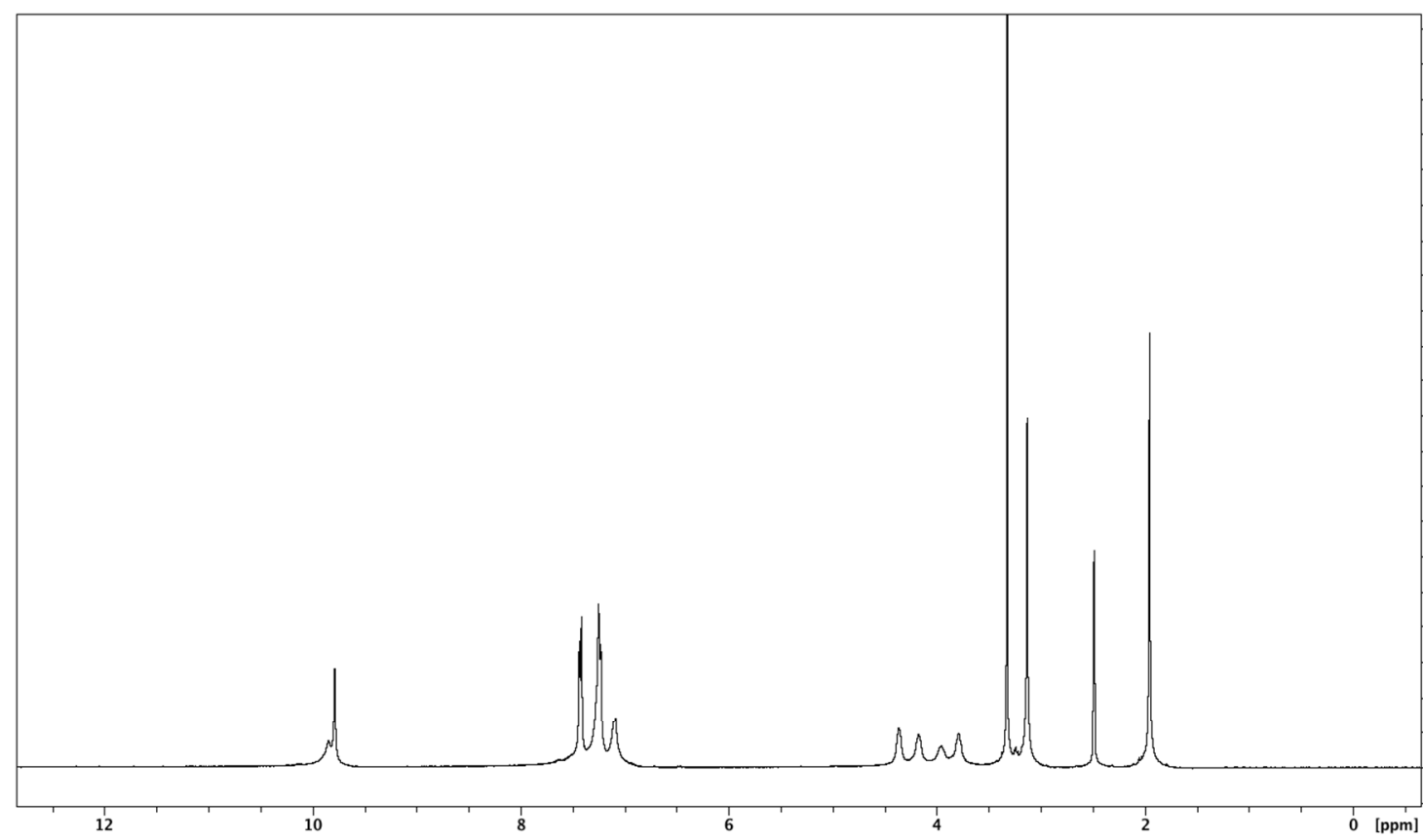

Figure S8-(k). $\quad{ }^{1} \mathrm{H}$ NMR spectrum of 7.

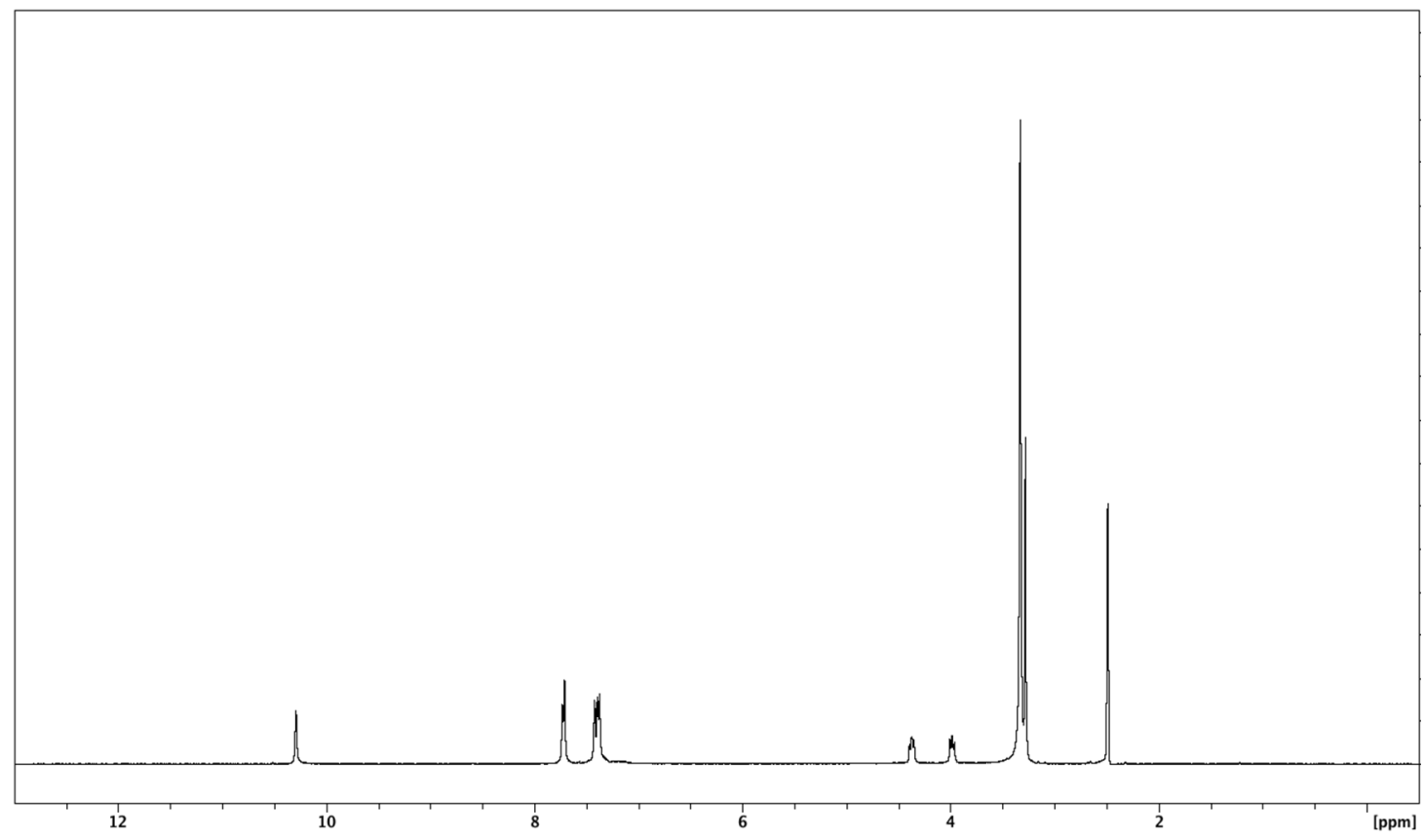

Figure S8-(l). $\quad{ }^{1} \mathrm{H}$ NMR spectrum of $\mathbf{8}$. 


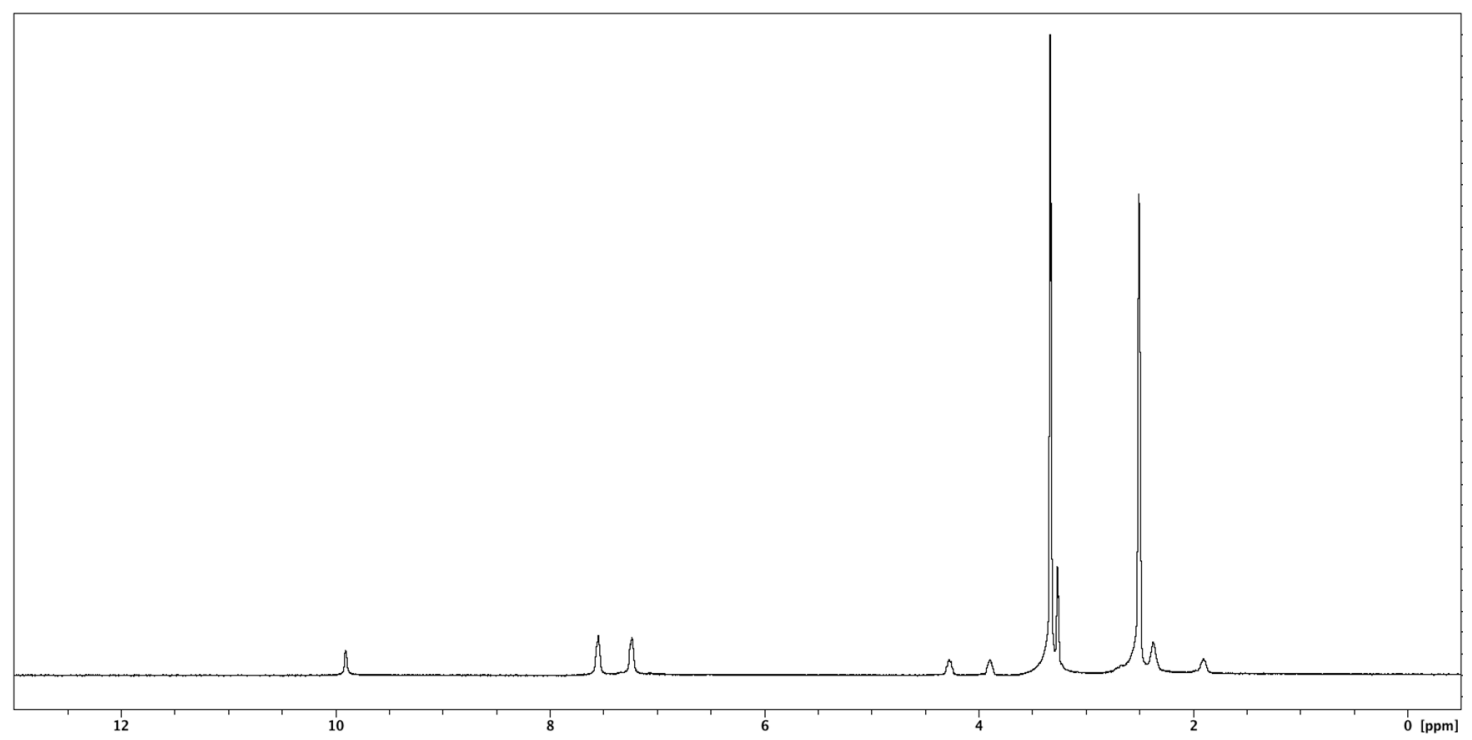

Figure S8-(m). $\quad{ }^{1} \mathrm{H}$ NMR spectrum of 9-C5.

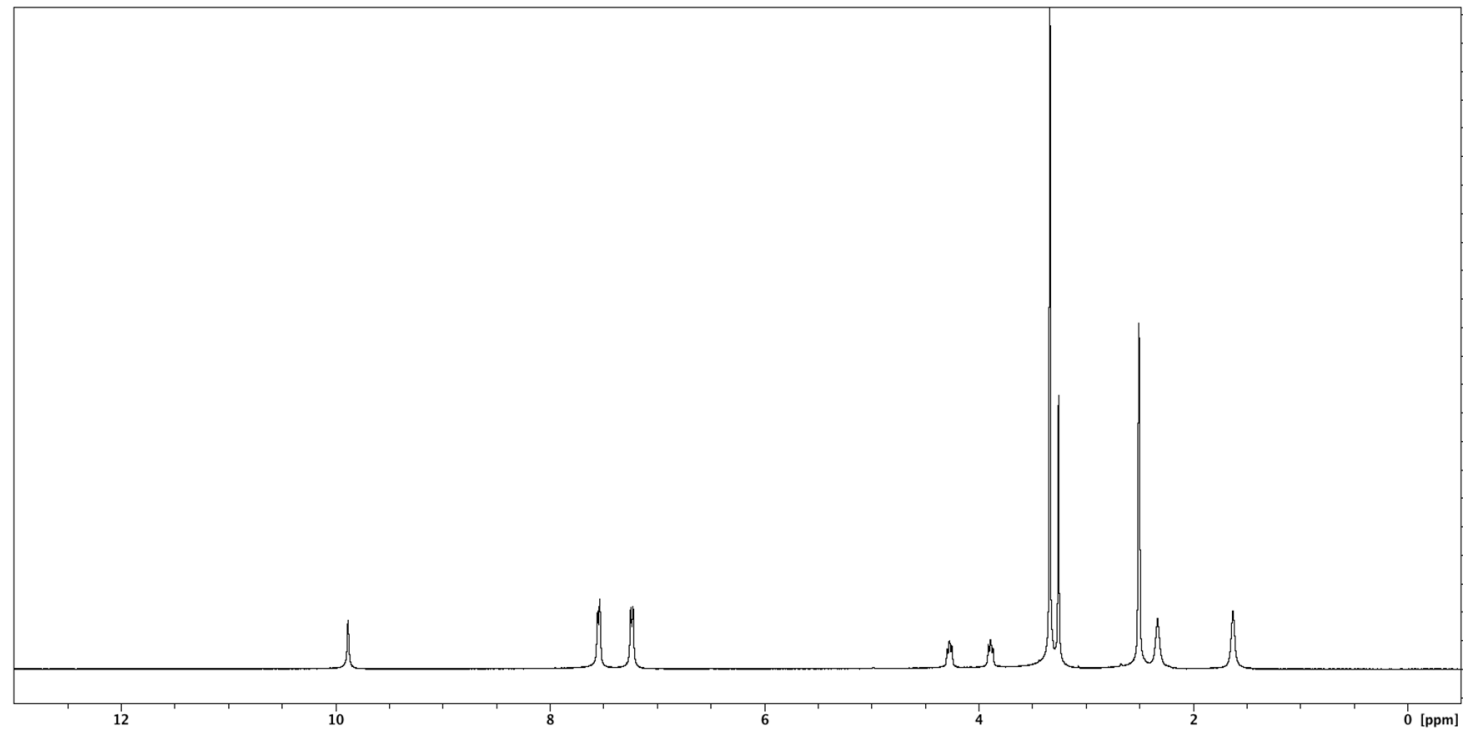

Figure S8-(n). $\quad{ }^{1} \mathrm{H}$ NMR spectrum of 9-C6. 


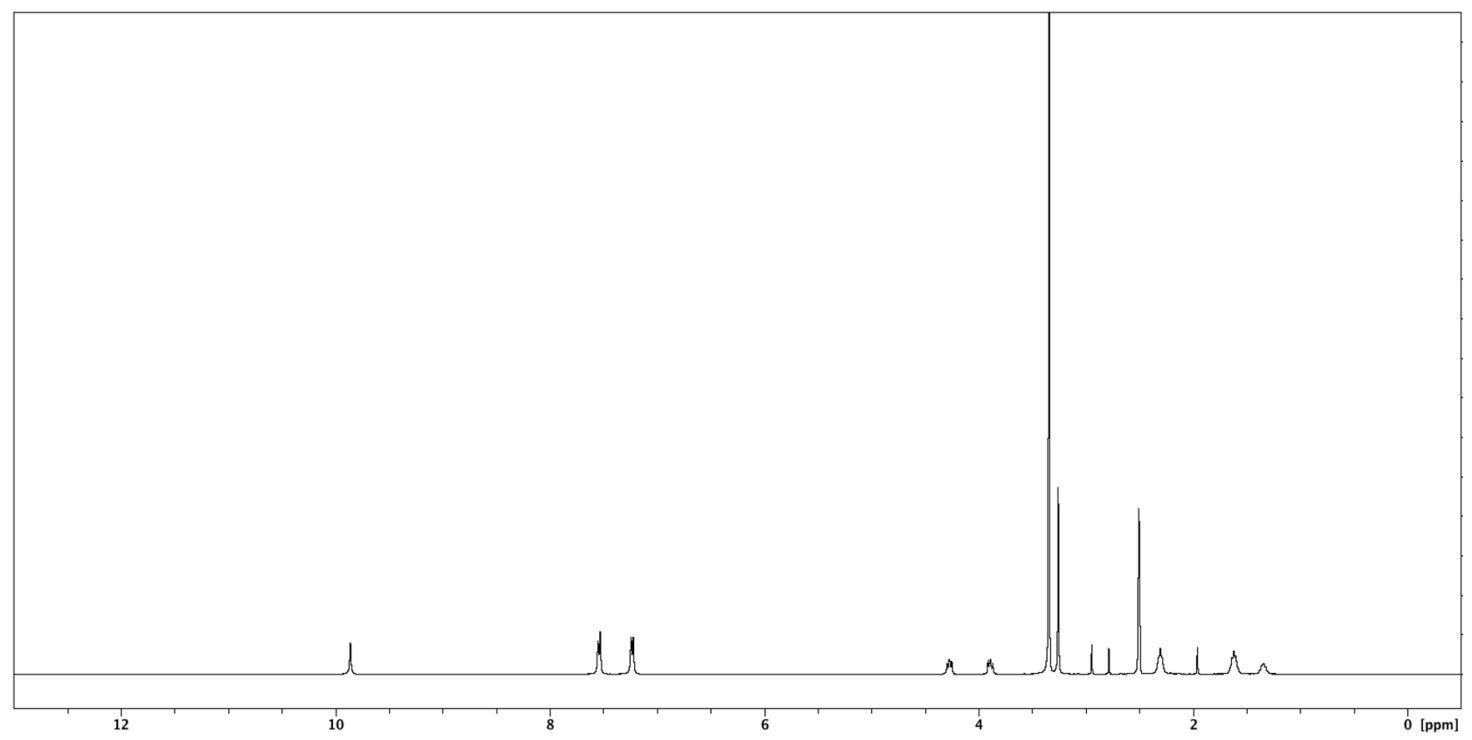

Figure S8-(o). $\quad{ }^{1} \mathrm{H}$ NMR spectrum of 9-C7.

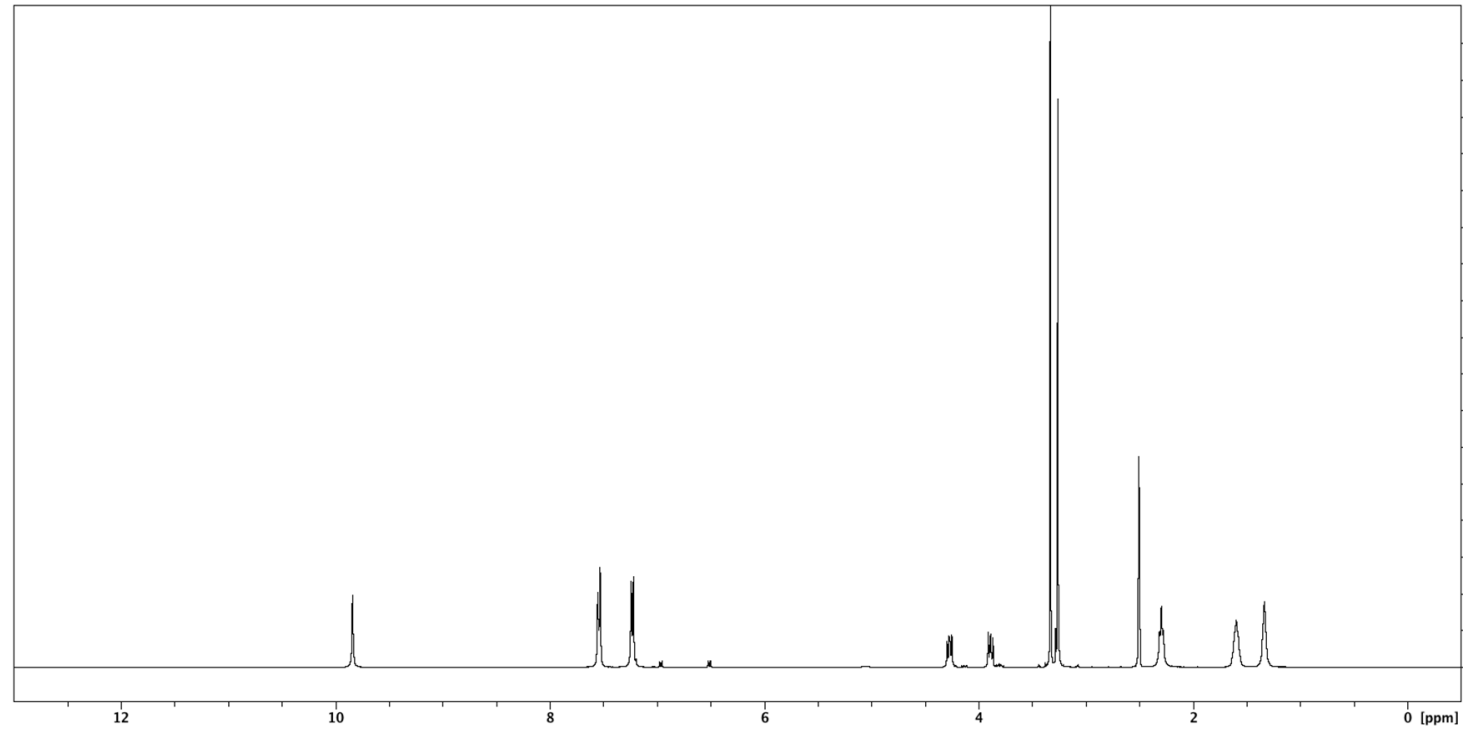

Figure S8-(p). $\quad{ }^{1} \mathrm{H}$ NMR spectrum of 9-C8. 


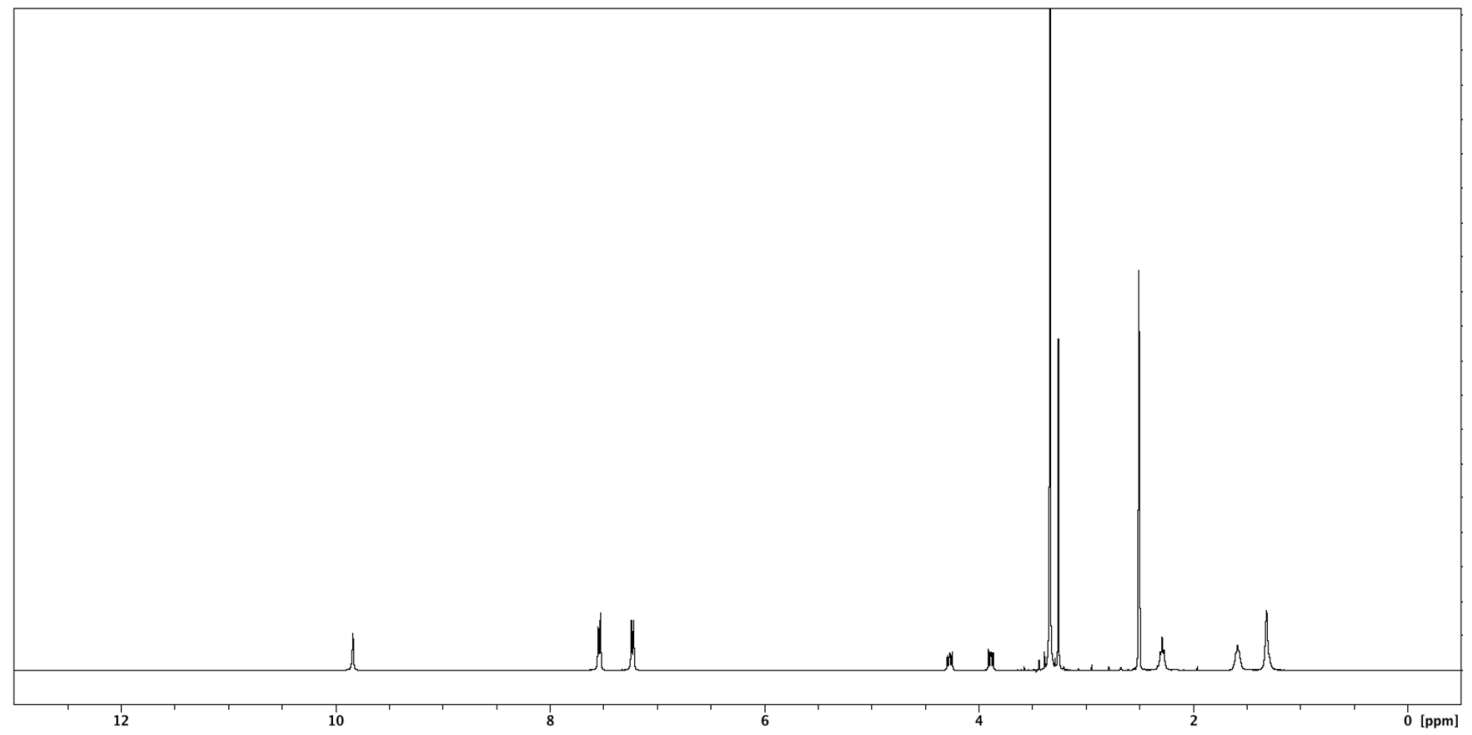

Figure S8-(q). $\quad{ }^{1}$ H NMR spectrum of 9-C9.

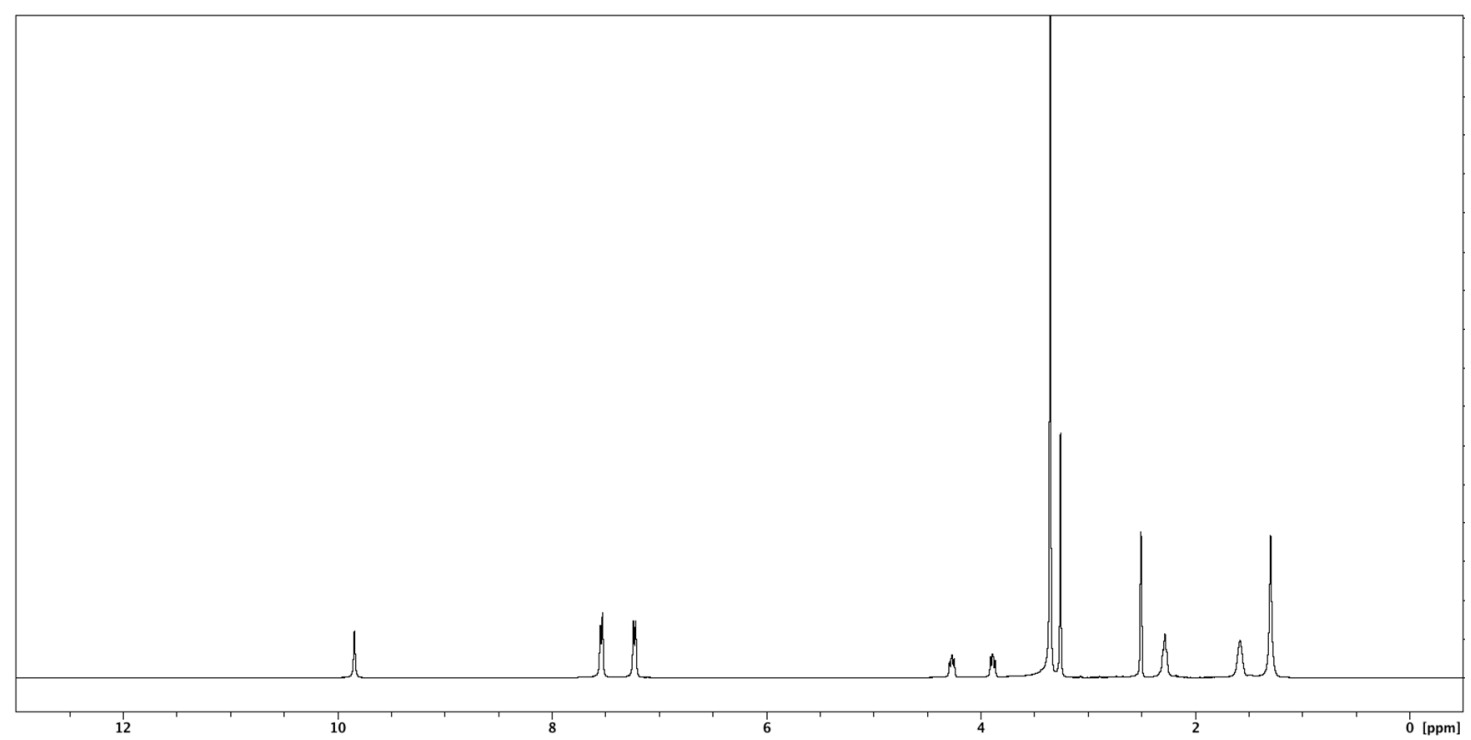

Figure S8-(r). $\quad{ }^{1} \mathrm{H}$ NMR spectrum of 9-C10. 


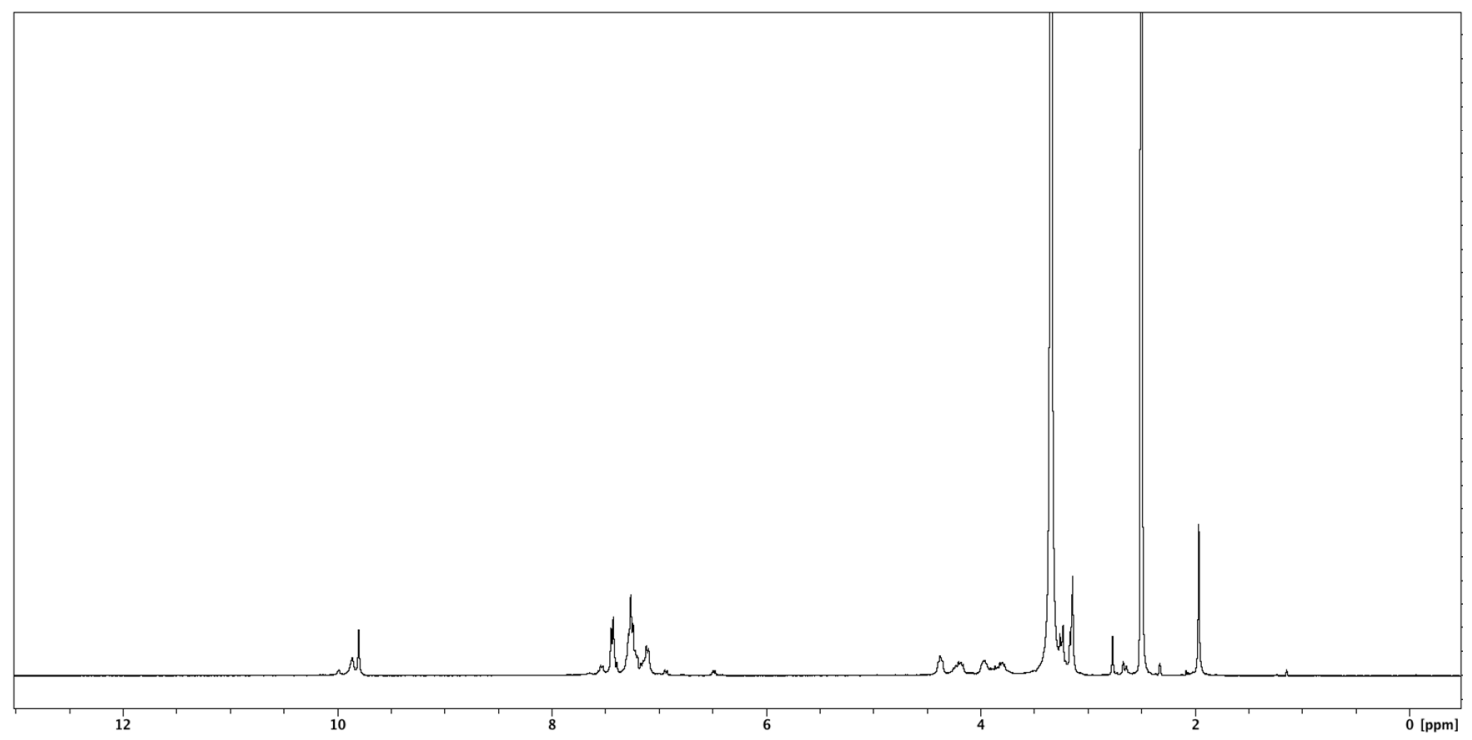

Figure S8-(s). $\quad{ }^{1} \mathrm{H}$ NMR spectrum of 10-C4.

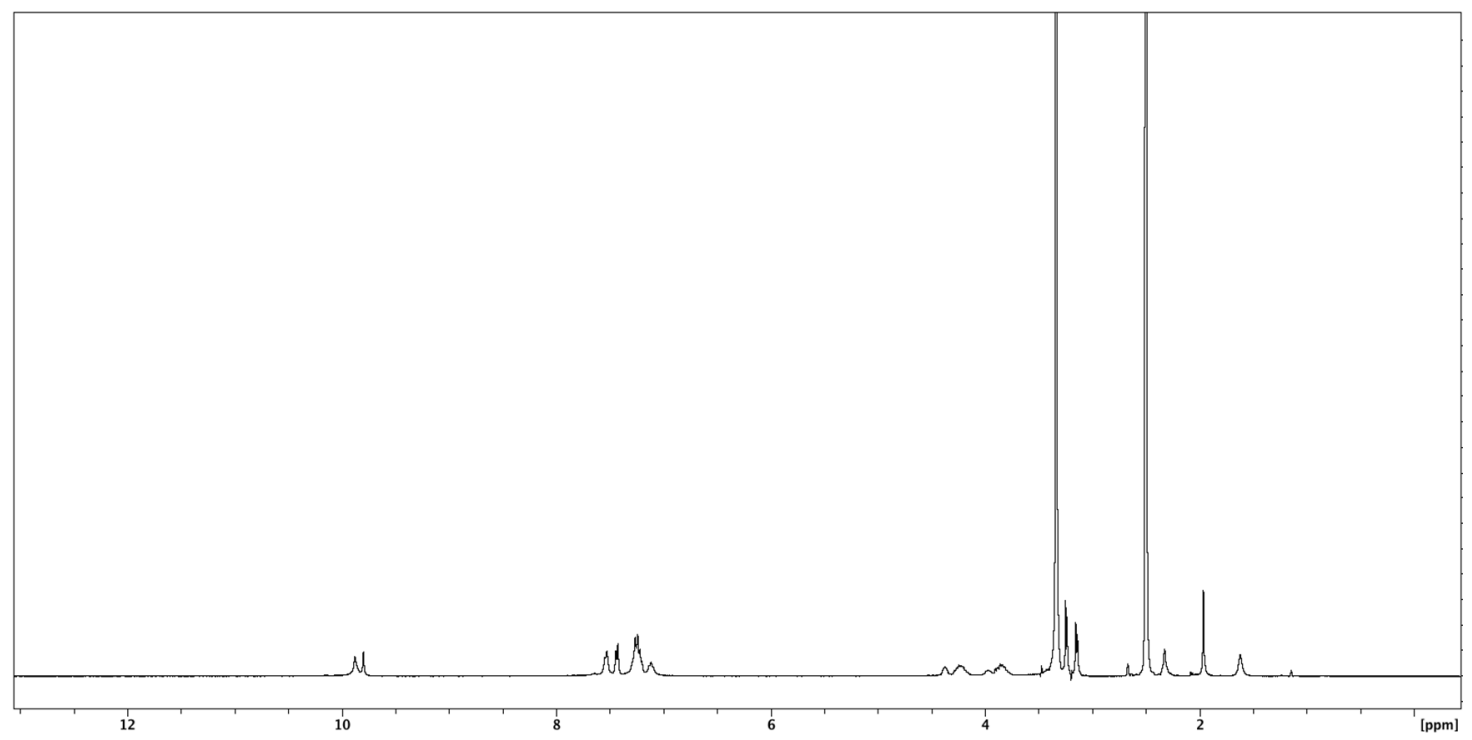

Figure S8-(t). $\quad{ }^{1} \mathrm{H}$ NMR spectrum of 10-C6. 


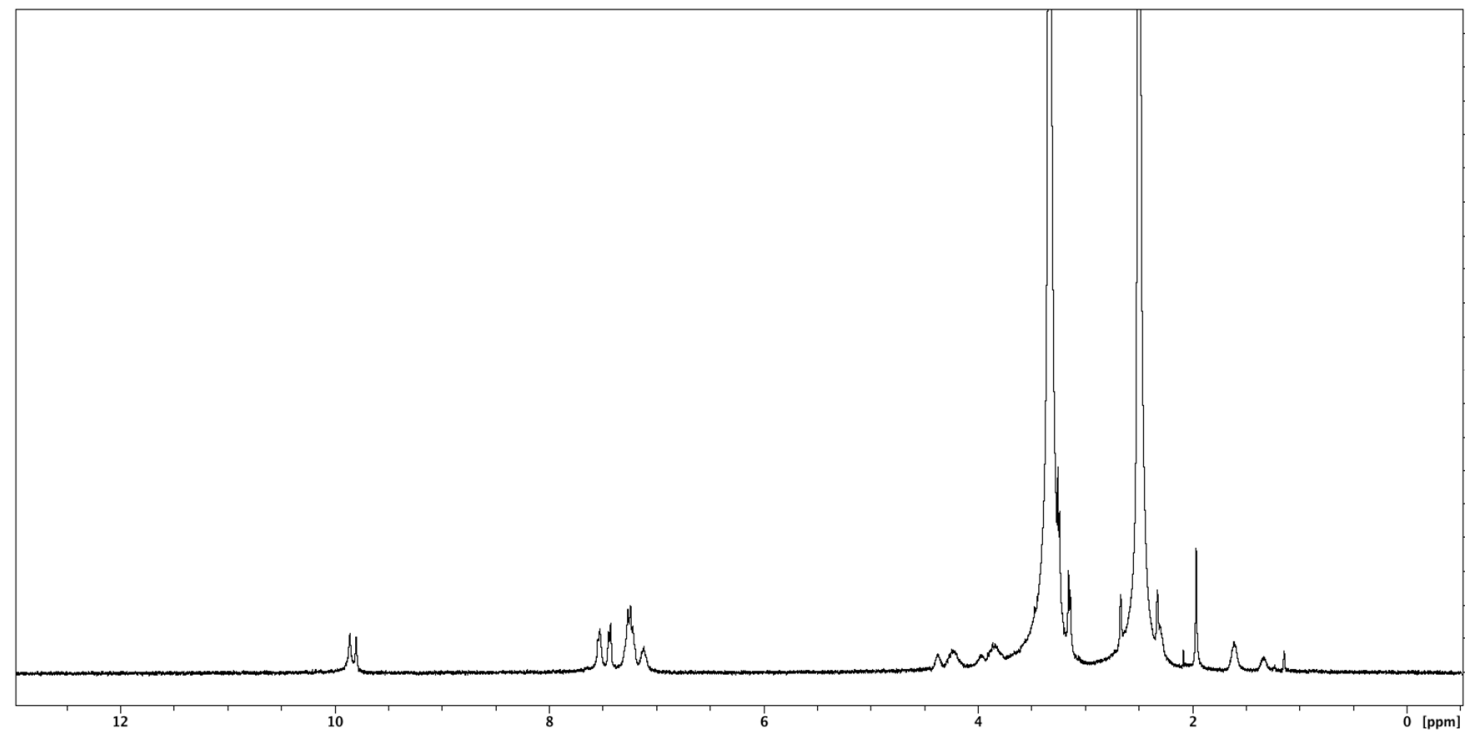

Figure S8-(u). $\quad{ }^{1} \mathrm{H}$ NMR spectrum of 10-C7.

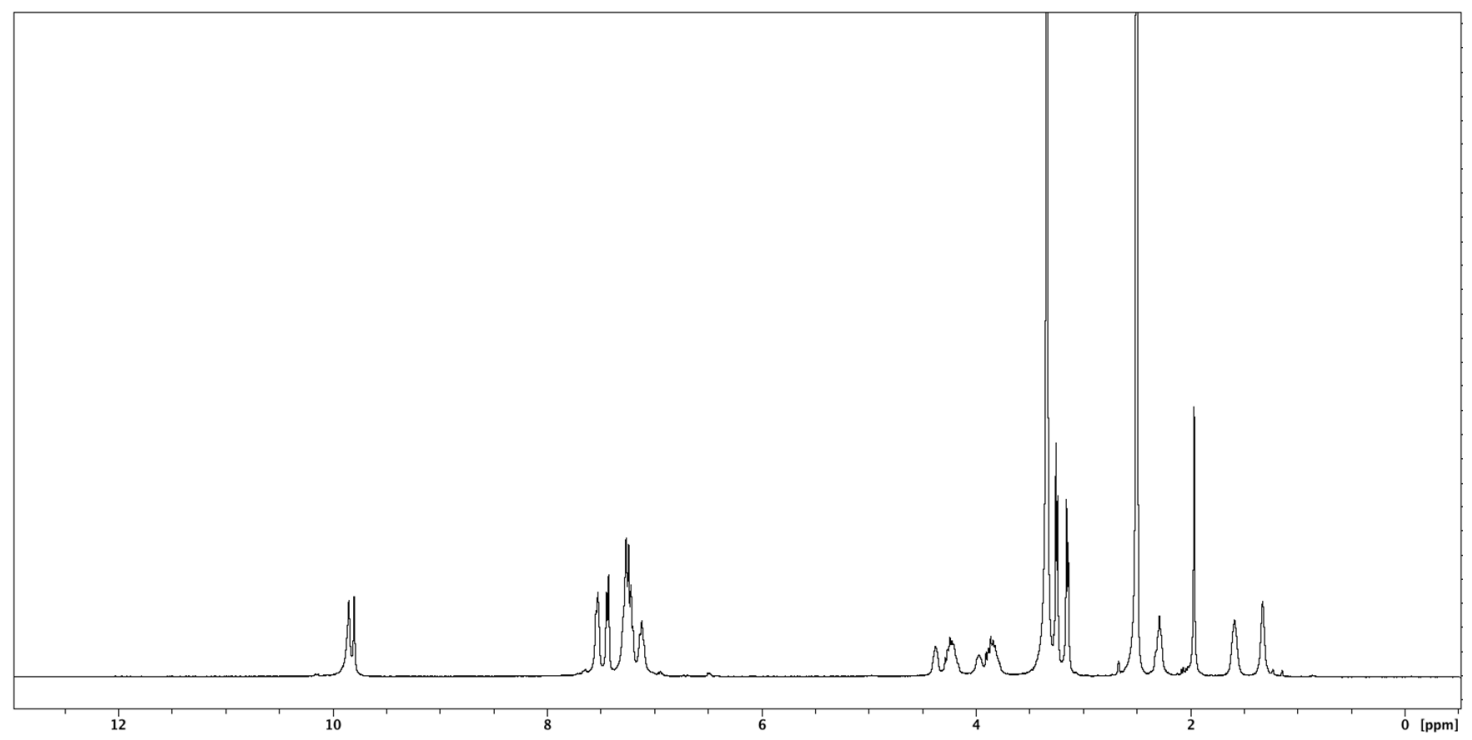

Figure S8-(v). $\quad{ }^{1} \mathrm{H}$ NMR spectrum of 10-C8. 


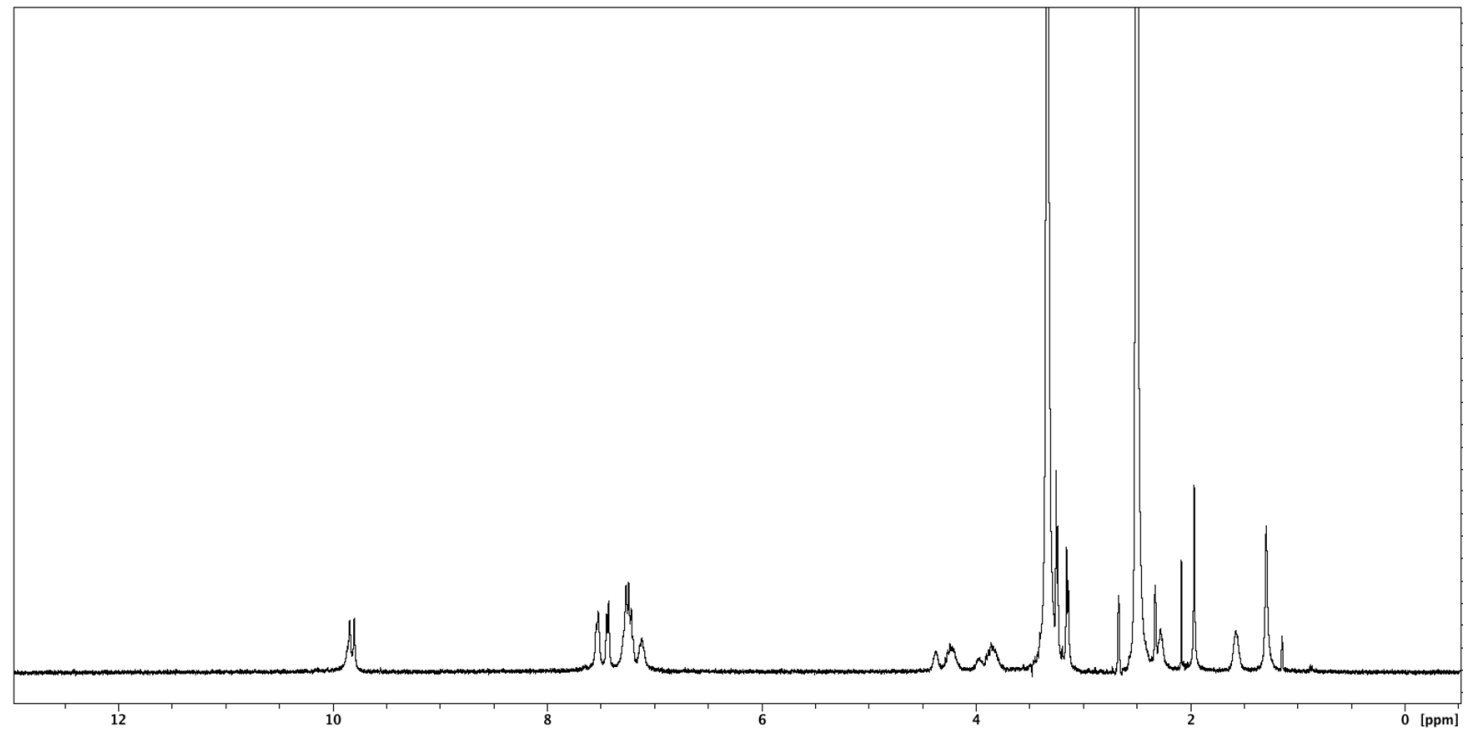

Figure S8-(w). $\quad{ }^{1} \mathrm{H}$ NMR spectrum of 10-C10. 
a

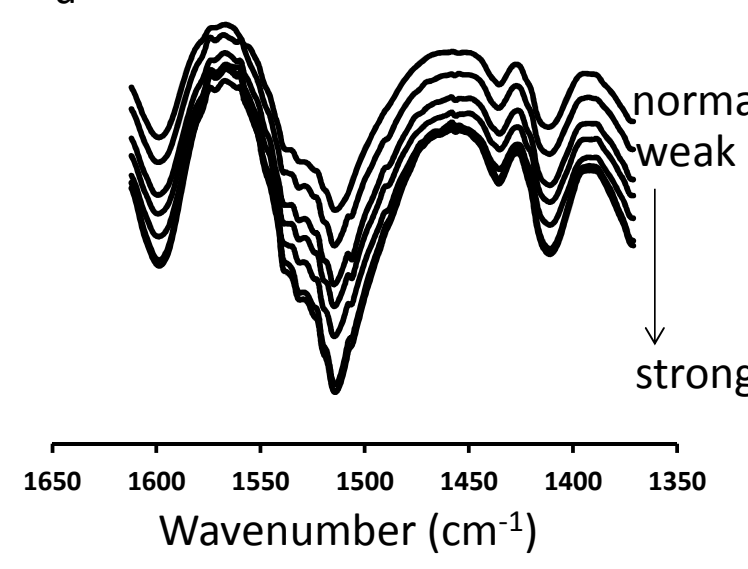

b

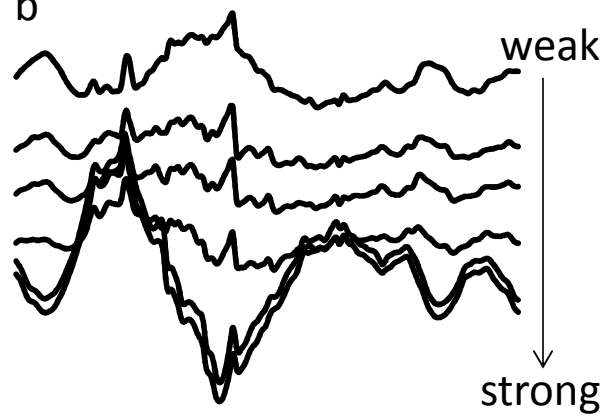

1650

$\begin{array}{llllll}1600 & 1550 & 1500 & 1450 & 1400 & 1350\end{array}$ Wavenumber $\left(\mathrm{cm}^{-1}\right)$

Figure S9. IR/ATR spectra of polyamide 7 film. a) Spectrum changes dependent on the mechanical pressure increase. Top is under no pressure, and below that the pressure (a.u.) was gradually increased. b) Differential spectra of the films under no pressure and a certain pressure. Pressure (a.u.) was increased from the top to the bottom. Clear differences under two strongest pressure (two bottoms) can be seen. 